ستخدام نموذج التوازن الجزئي في قياس أثر سياسات التحرر الأقتصادي علي محصول القمح هشام علي حسن الجندي

معهد بحوث الاقتصاد الزراعي - مركز البحوث الزين الزر اعية

مقدمه:

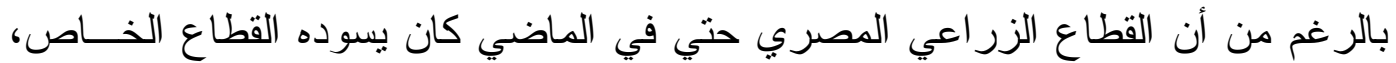

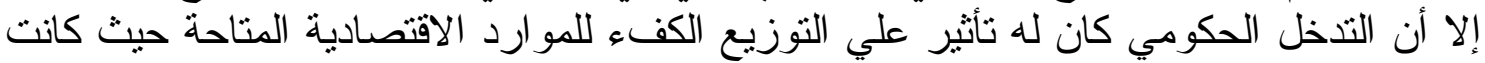

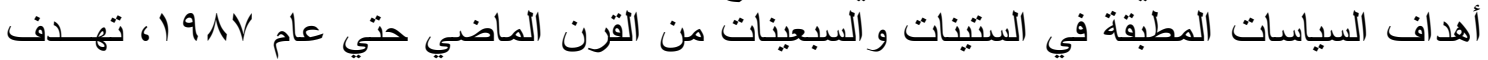

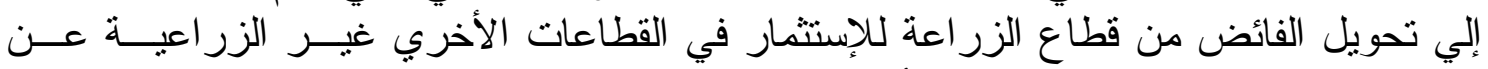

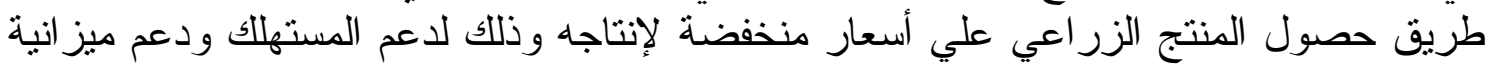

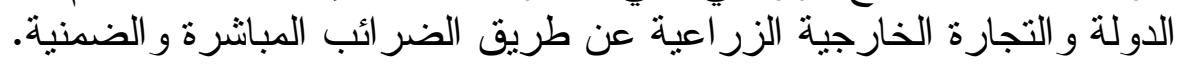

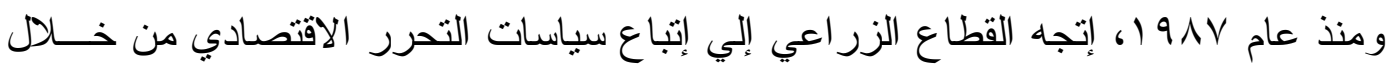

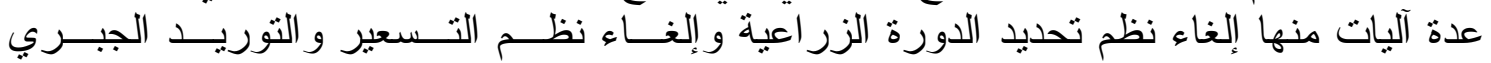

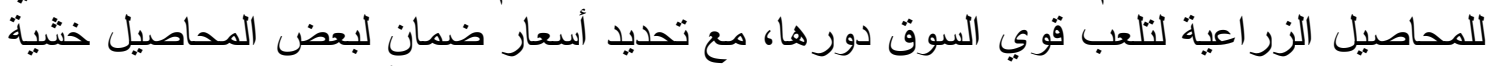

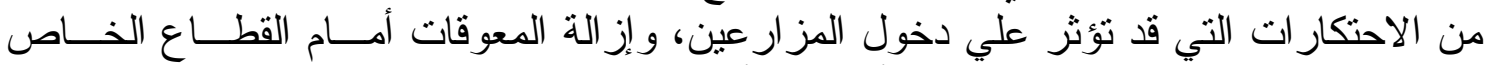

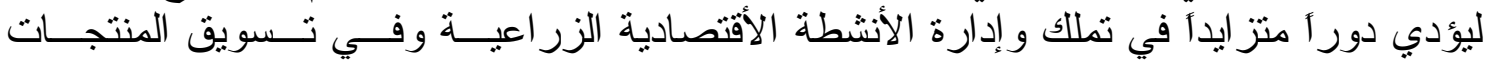

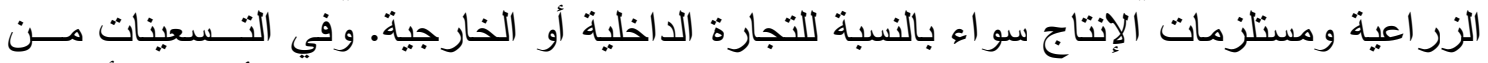

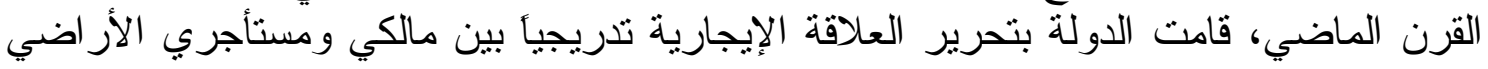

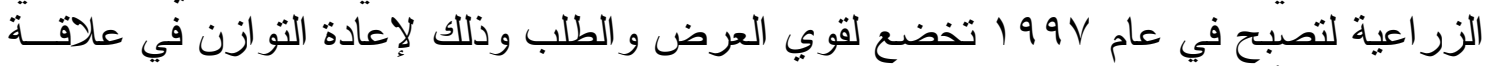

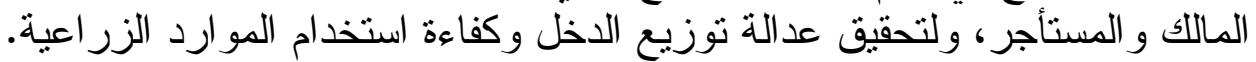

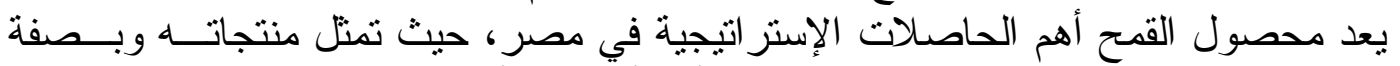

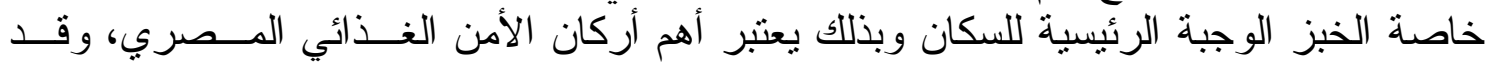

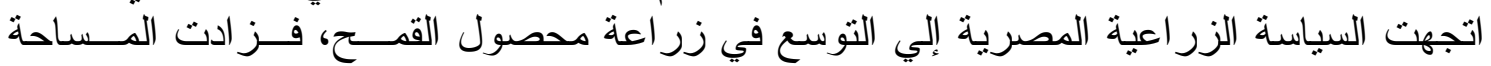

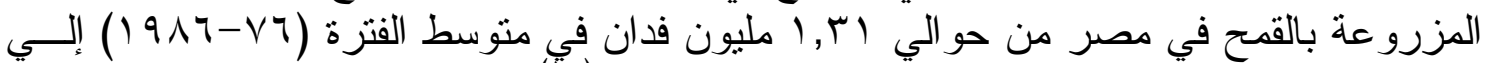

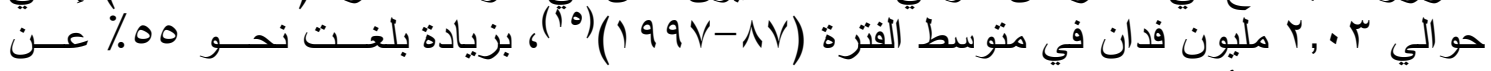

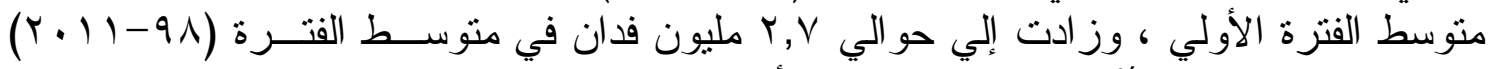

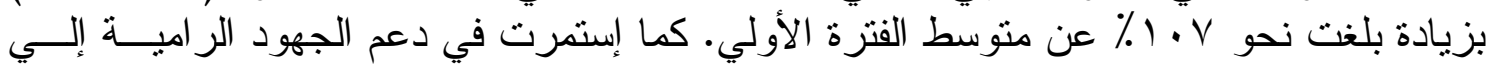

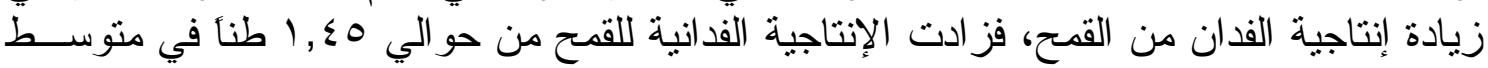

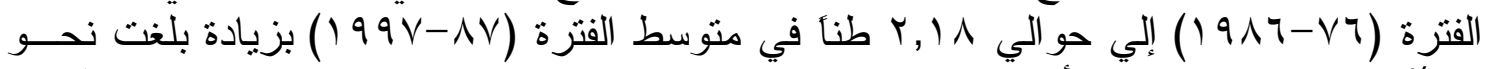

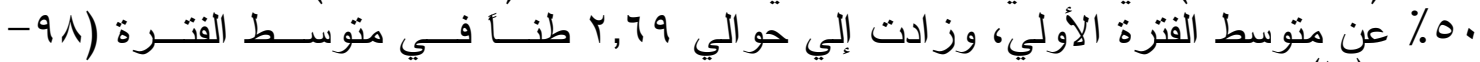

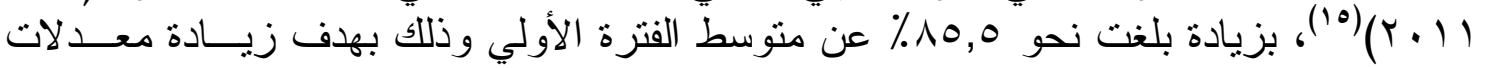
الاكتفاء الذاتي منه و التي بلغت نحو

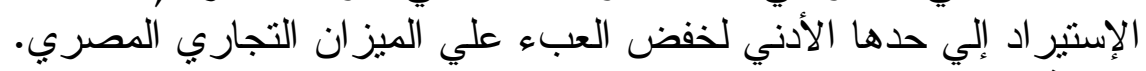

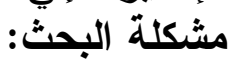

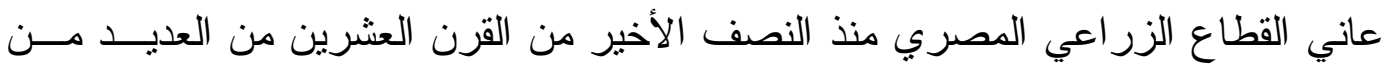

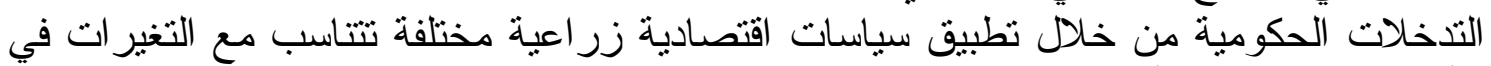

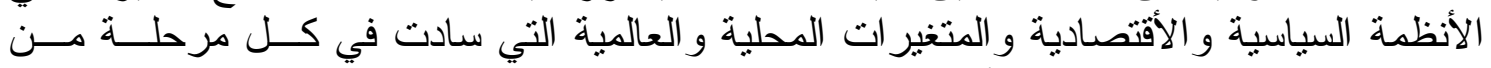

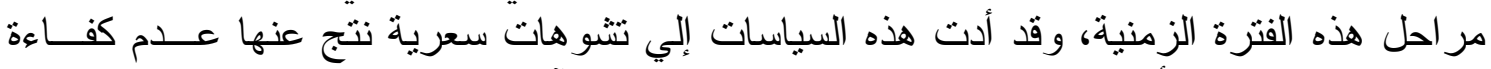

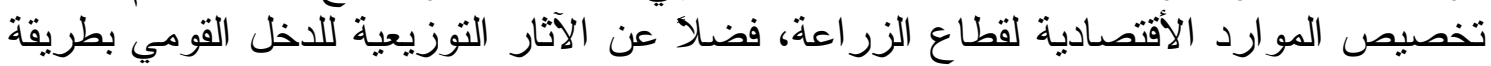

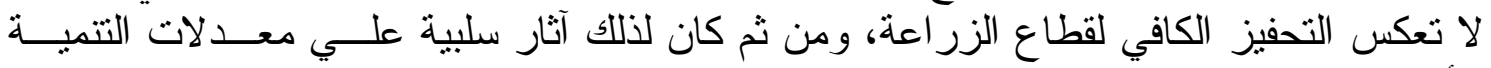

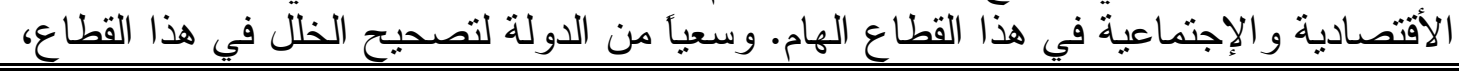

Received on: 5/2/2014 Accepted for publication on: 2/3/2014

Referees: Prof. Ahmed A. M. Abdel-fadil Prof. Abd Alnabi B. Abead 


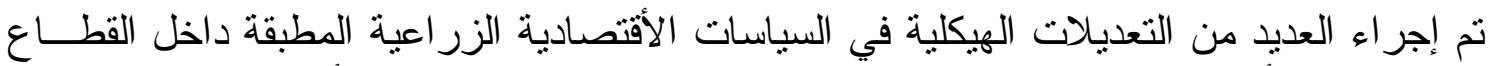

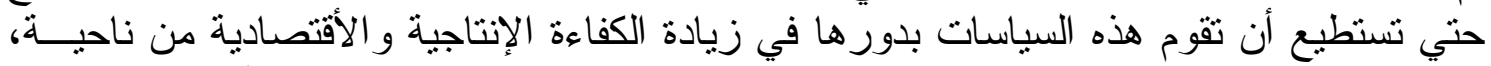
وضمان زيادة و إستقر ار الدخل المزر هذه وني وتحسين الرفاهية الإجتماعية من ناحية أخري.

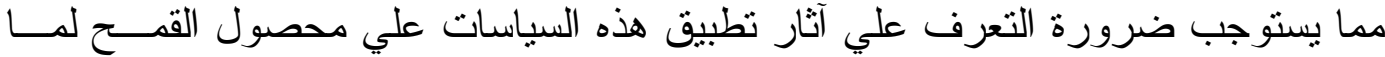

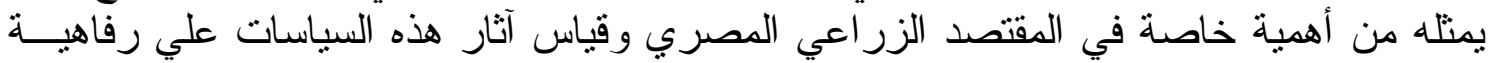

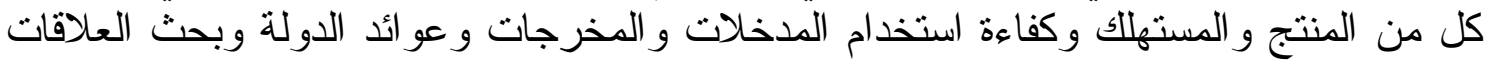

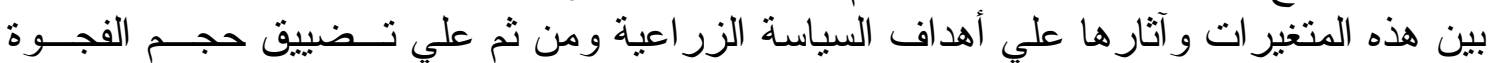
القمحية. أهداف البحث:

يستهدف البحث تحقيق الأهداف البحثية التالية:

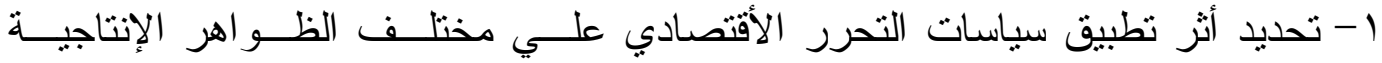

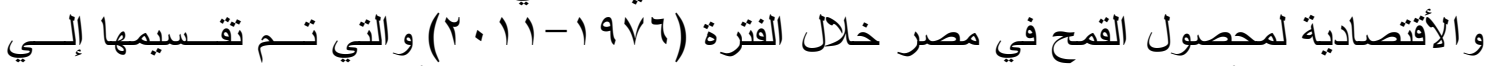

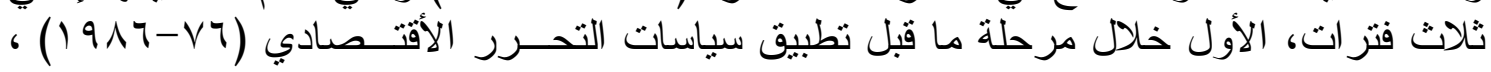

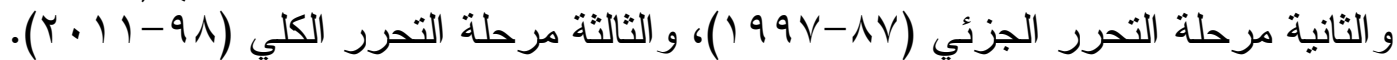

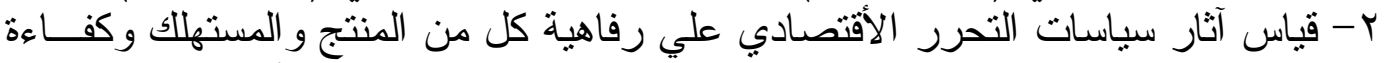

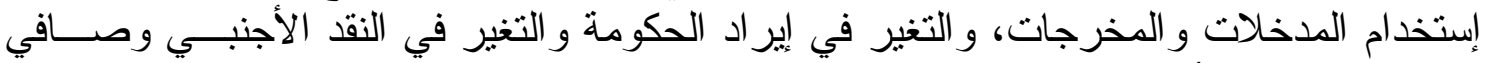

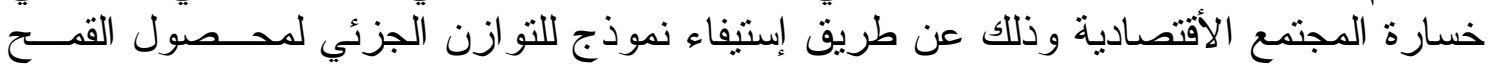

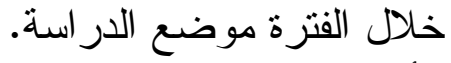

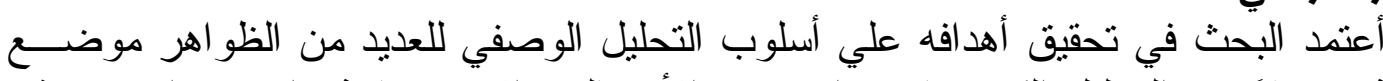

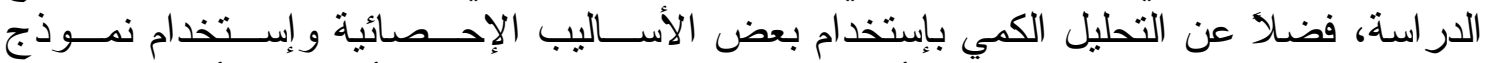

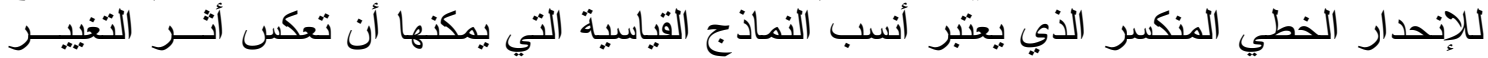

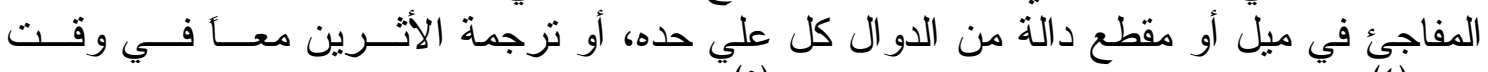

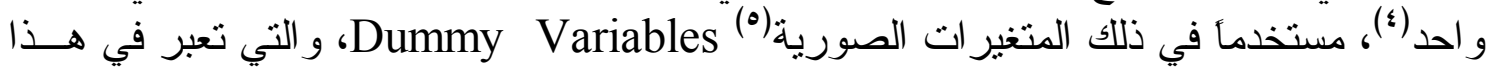

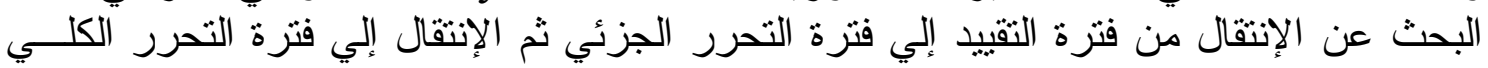

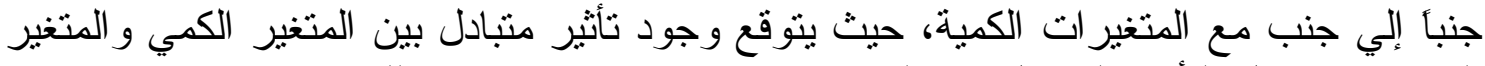

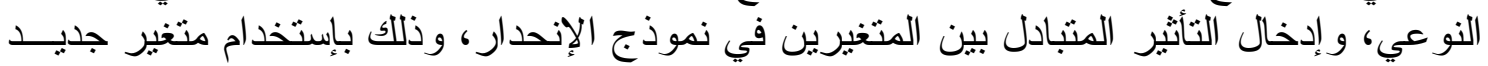

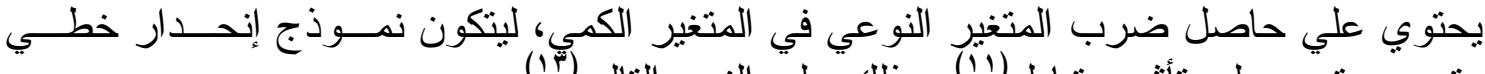

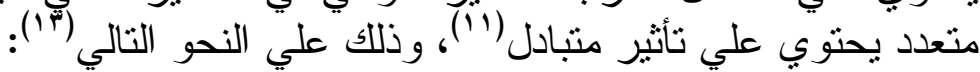

( $)$

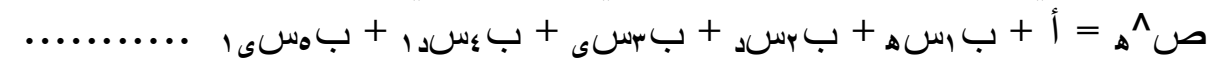

حيث: ص ^ه = تشير إلي القيمة التقديرية للظاهرة موضع الدر اسة في السنة هـ.

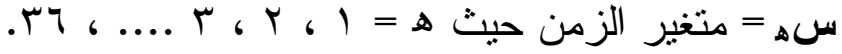

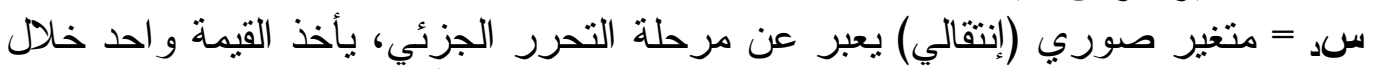

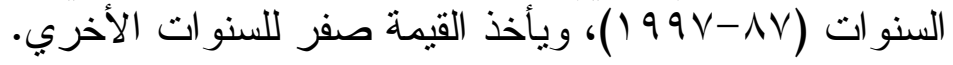

$$
\text { سى = حاصل ضرب سه × سد. س. }
$$

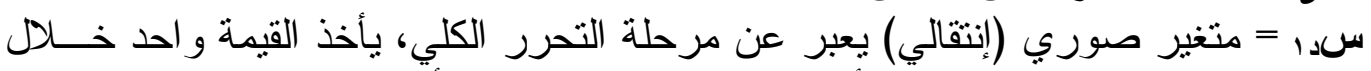

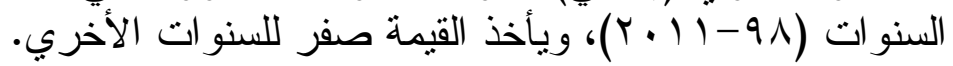

$$
\text { سى, = حاصل ضرب سه × سد ا. }
$$




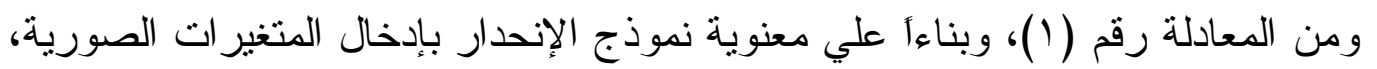

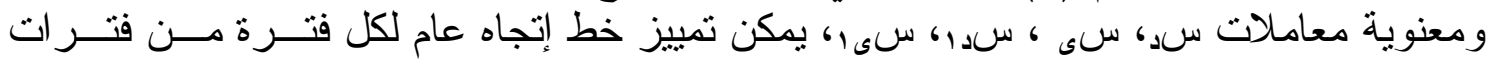

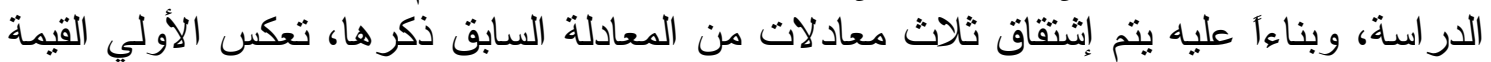

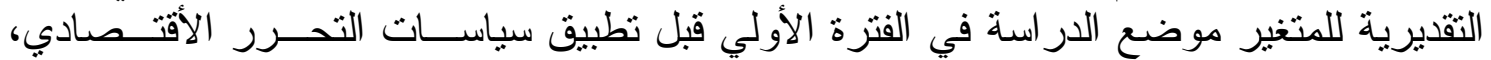
ويتمنت شكل هذه المعادلة في الصورة التالية:

وتعكس المعادلة الثانية، القيمة التقديرية للمتغير موضع الدر اسة في الفترة الثانية (فترة

التحرر الجزئي) ويتمثل شكل المعادلة في الصورة الصنة التالية:

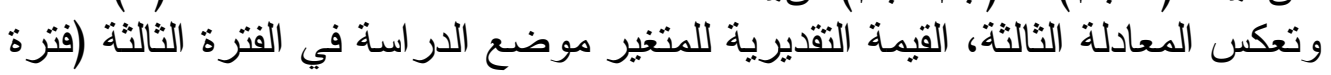

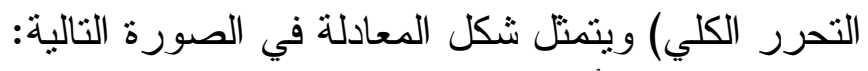

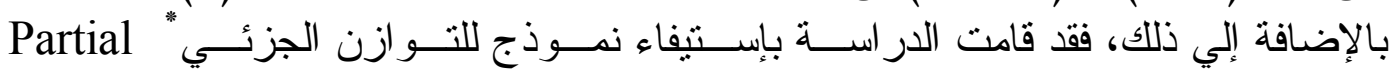
Equilibrium Model نموذج التو ازن الجزئي من مجموعة من المعادلات فيانها كالتالي (؟)،(^):

(1) $\mathrm{NSL}_{\mathbf{P}}=0.5\left(\mathrm{Q}_{\mathbf{W}}-\mathrm{Q}\right)\left(\mathrm{P}_{\mathbf{W}}-\mathrm{P}_{\mathbf{P}}\right)$

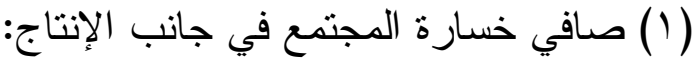

(2) $\mathrm{NSL}_{\mathbf{C}}=0.5\left(\mathrm{C}_{\mathbf{W}}-\mathrm{C}\right)\left(\mathrm{P}_{\mathbf{C}}-\mathrm{P}_{\mathbf{W}}\right)$

(3) $\mathrm{NSL}=-\left(\mathrm{NSL}_{\mathbf{P}}+\mathrm{NSLc}\right)$

(4) $G_{\mathbf{P}}=Q\left(P_{\mathbf{p}}-P_{\mathbf{W}}\right)-\mathrm{NSL}_{\mathbf{P}}$ (ع) عو ائد الرفاهية للمنتجين (فو ائض المنتجين):

(5) $\mathrm{G}_{\mathbf{C}}=\mathrm{C}\left(\mathrm{P}_{\mathbf{W}}-\mathrm{P}_{\mathbf{C}}\right)-\mathrm{NSL}_{\mathbf{C}}$

(6) $d F=-P_{w}\left(Q_{w}-Q+C-C_{W}\right)$

(7) $d G=Q\left(P_{W}-P_{P}\right)-C\left(P_{W}-P_{C}\right)$

$$
\begin{aligned}
& =-\mathrm{NSL}-\mathrm{G}_{\mathbf{P}}-\mathrm{G}_{\mathbf{C}} \\
& =-(3+4+5)
\end{aligned}
$$

= Qw = Q $=$ Q = CW = C أسعار الحدود. P P P = PP = PC 
ويقوم النموذج علي فرضين أساسيين، أولهما أن الأسعار تساوي متوسط التكـاليف (أمسـا

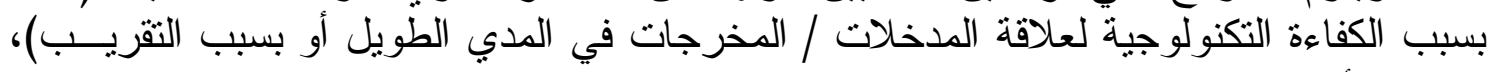

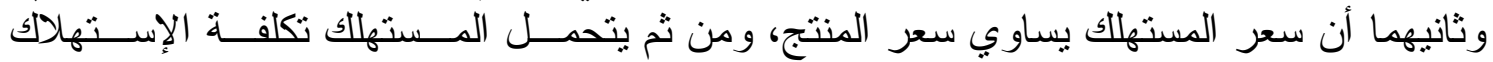

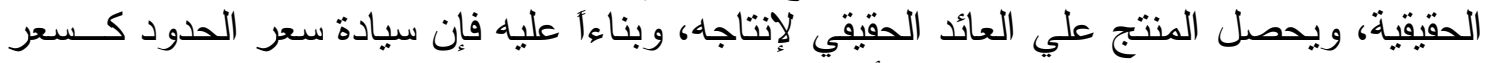

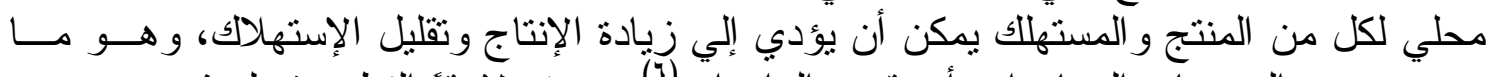

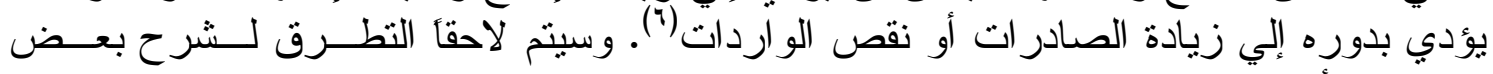

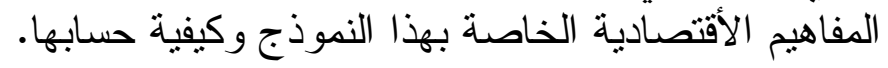
مصادر البيانات:

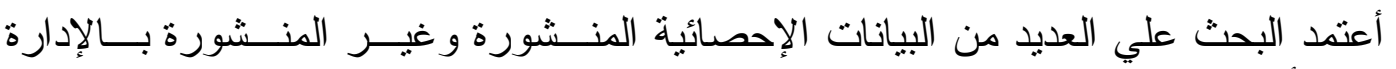

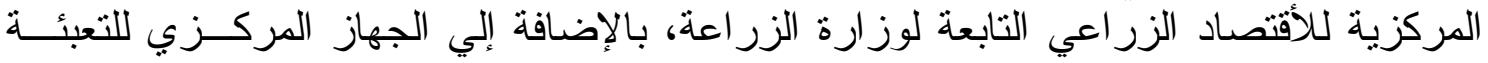

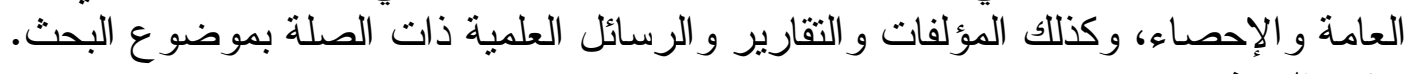

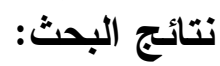

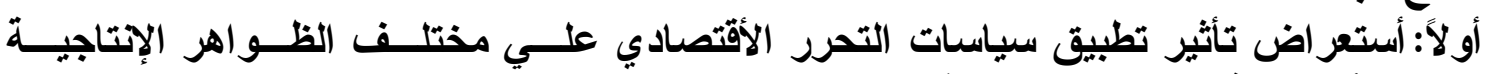

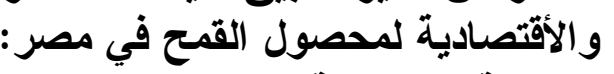

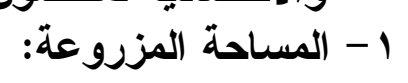

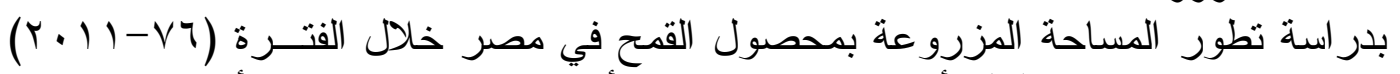

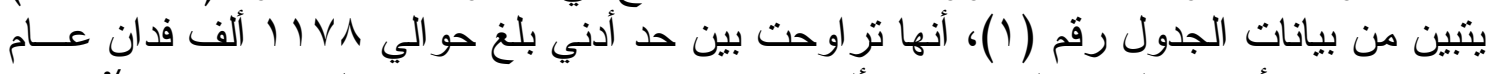

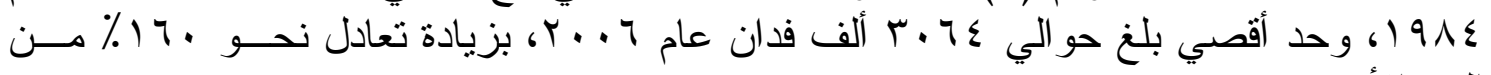

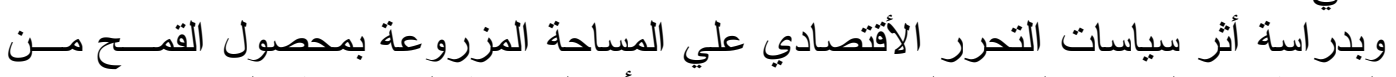
الحد الأدني.

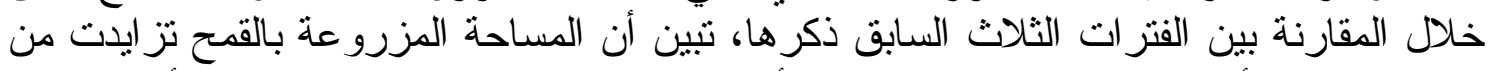

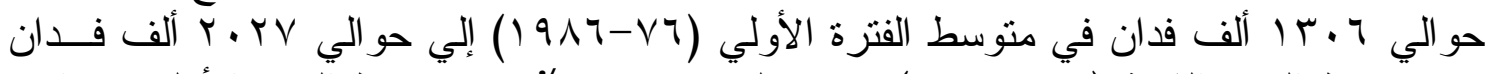

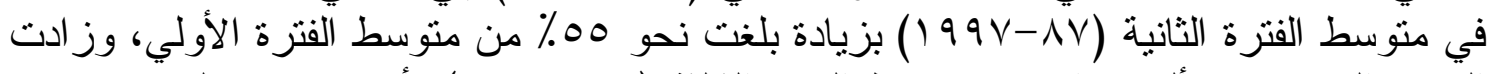

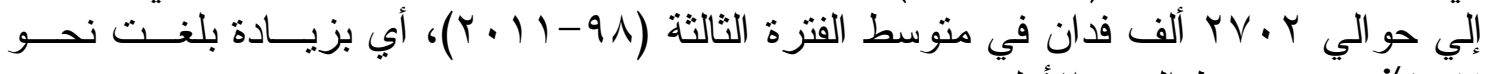

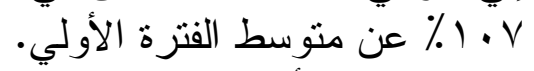

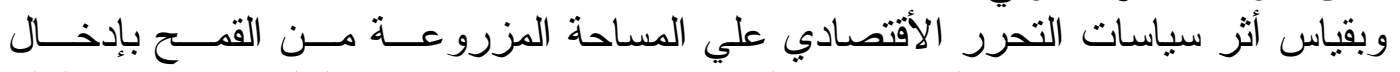

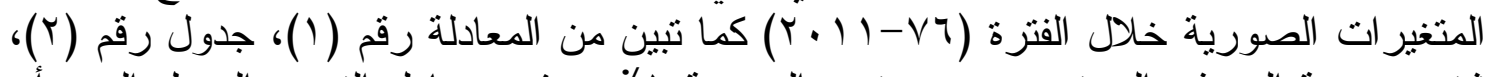

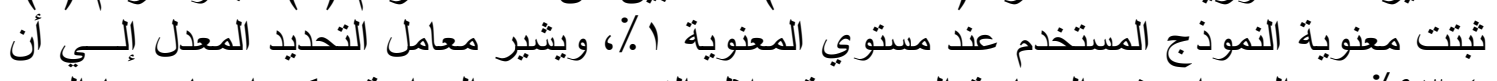

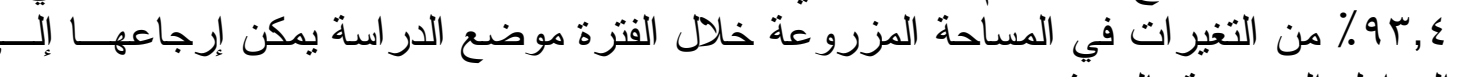

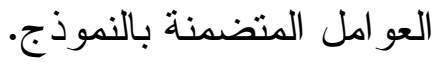


جدول رقم (1): تطور مختلف الظواهر الإتتاجية والأقتصادية لمحصول القمح في مـصر في الفي

\begin{tabular}{|c|c|c|c|c|c|c|}
\hline لإلفته المتاح & ألف اردية & جنيه/طن المزرعي & ألف طن الإنتاج & طن الإنتاجية & ألمزروعة فدانة & السنة \\
\hline$\leqslant 90$. & 1919 & $\leqslant V, 1$ & 197. & $1, \varepsilon$. & 1497 & $19 \vee 7$ \\
\hline r & מצr & $0 \leqslant, 1$ & 1798 & $1, \leqslant 1$ & $M \cdot V$ & $19 V V$ \\
\hline $7 V 10$ & 0.07 & $71, V$ & س 19M1 & $1, \varepsilon$. & |r人| & $19 \vee 1$ \\
\hline voo. & OTYV & $7 \varepsilon$, & $110 \mathrm{~V}$ & $1, r \varepsilon$ & $|19|$ & $19 \vee 9$ \\
\hline $7 \leq \vee \wedge$ & $\varepsilon q . r$ & $\wedge \wedge, \cdot$ & 1897 & דז, 1 & דצדו & 191. \\
\hline$\Lambda E Y V$ & 7000 & 91,1 & $19 \Gamma$ & $1, \mu_{\Lambda}$ & $1 \leq \ldots$ & 1911 \\
\hline$\vee \leq \wedge \wedge$ & $0 \leq \leqslant \Lambda$ & $\wedge I, V$ & $\mathrm{r} .1 \mathrm{~V}$ & $1, \leq V$ & ITVE & $19 \wedge r$ \\
\hline V700 & תTH & $1.9,9$ & 1997 & 1,01 & ITr. & $19 \wedge 4$ \\
\hline$\Lambda \vee \leqslant \Lambda$ & 7094 & $\mid r \varepsilon, r$ & $111 \varepsilon$ & $1,0 \leqslant$ & $11 \vee \wedge$ & $191 \varepsilon$ \\
\hline$\Lambda T \cdot \varepsilon$ & $7) \leq 7$ & $|V|, V$ & INVT & 1,01 & 1117 & 1910 \\
\hline VVMI & OAT. & $r Y \leq, q$ & $19 r \wedge$ & 1,7 . & $1 Y \cdot T$ & 1917 \\
\hline$V \backslash \wedge V, r$ & or $\leqslant r, V$ & $1 \cdot r_{,} \cdot$ & 1194 & 1,0 & $11 \% .7$ & متوسط الفترة \\
\hline A.r. & ovi. & YY., T & TVYT & 1,91 & سקו & $191 \mathrm{~V}$ \\
\hline$V \vee \leq 1$ & $\leqslant 97$. & rTV, & 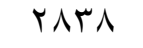 & $r, \ldots$ & $1 \leqslant r r$ & $19 \wedge 1$ \\
\hline VYTT & EYOY & $\leqslant \Psi \neg, 0$ & 円人 & $r, \wedge$ & سז10 & 1919 \\
\hline $9 r \cdot 1$ & $0 \leq V \leq$ & $\varepsilon V \Gamma, r$ & $\varepsilon r V$. & $r, 1 \wedge$ & 1900 & 199. \\
\hline$q \pi \leqslant V$ & $\leqslant \neg \wedge \wedge$ & $\leqslant 9 \wedge, 1$ & $\varepsilon \varepsilon \wedge \mu$ & $r, \cdot r$ & TrIO & 1991 \\
\hline qTVT & or.r & or $7, \wedge$ & $\leq 719$ & $Y, Y_{1}$ & $r .9 r$ & $199 r$ \\
\hline qTVV & $\varepsilon 90 Y$ & or^, 9 & ع & r & $Y|V|$ & 1994 \\
\hline . & ૫ヘヘル & or $\leqslant, 0$ & $\varepsilon \varepsilon \mu V$ & $r, 1$. & 411 & 1998 \\
\hline $1.71 \mathrm{~V}$ & $0 \leqslant 71$ & OTY,V & OVYO & $r, Y \wedge$ & rolr & 1990 \\
\hline 111.0 & $09 . r$ & $7 \varepsilon \cdot, \varepsilon$ & OVTO & $r, r v$ & $r \leqslant Y)$ & 1997 \\
\hline ס 1.0 & $\varepsilon q \mu q$ & 777,9 & ONHV & هب, & $r \leq \wedge T$ & 1998 \\
\hline $97 Y \cdot, 5$ & Orr., r & $\varepsilon \wedge \varepsilon, Y$ & $\varepsilon \leqslant Y \nearrow, V$ & $r, 1 \wedge$ & $r \cdot r T, 0$ & متوسط القترة \\
\hline IITVY & OTYV & ฯА., • & $7.9 \leq$ & $r, O Y$ & $r \leq Y)$ & 1991 \\
\hline $1 \cdot \leqslant 1 V$ & $\varepsilon 19 V$ & ฯง & Tr & $T, T V$ & rrvq & 1999 \\
\hline 111 ro & سוا & 79т,. & 7077 & $Y, T V$ & $r \leq 7 r$ & $r \ldots$ \\
\hline 11119 & 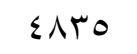 & $v \cdot, \cdot \cdot$ & TYON & $Y, T V$ & & $r \ldots 1$ \\
\hline $117 r V$ & sorq & $\vee \backslash \wedge, \cdot$ & TIYY & $r, V$. & $r \leq 0$. & $r \ldots r$ \\
\hline 1.947 & $\varepsilon .70$ & V $T \cdot, \cdot$ & $7 \wedge \leqslant 7$ & $r, V T$ & ro. 1 & $r \ldots r$ \\
\hline I 1 Vos & $\varepsilon r q V$ & $1 \cdots$, & VIA & $r, V T$ & $r 7.7$ & $r \ldots \varepsilon$ \\
\hline מוT & OVVT & $11 \% \cdot$, & $\Lambda) \leq$. & $r, v r$ & rq10 & $r \ldots o$ \\
\hline IE.Ar & $0 \wedge 1$. & $11 \times 7$, & NTVT & $r, V$. & $r .7 \leq$ & $r \ldots q$ \\
\hline ITVVY & 0911 & 1104. & VTVA & $r, V Y$ & YVIT & $r . r v$ \\
\hline $1 \leq 0 \leq 7$ & $\varepsilon \cdot V \mu$ & roor, & VqV & $r, V T$ & rqr. & $r . \Lambda$ \\
\hline $1 \leqslant 094$ & $7 \leq Y)$ & ז, & سOY & $r, V I$ & rqu. & $r . . q$ \\
\hline I rqv & TVYV & r, & 8179 & qr, & r. & $r \cdot 1$. \\
\hline ITAVA & 9111 & $r r \leq 7, V$ & ArVi & r, Vo & $r . \leqslant q$ & $r .11$ \\
\hline 1 I $\wedge \vee 0,1$ & $0 \leq 7 Y, 1$ & $1 Y 11,9$ & VYTV, Z & $r, 79$ & $r V \cdot r, r$ & متوسط الفترة \\
\hline
\end{tabular}

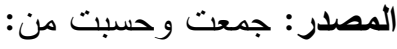

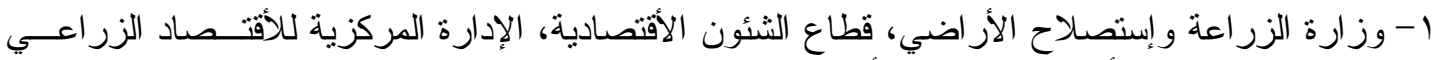

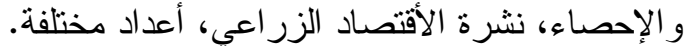
ץ- الجهاز المركزي للتعبئة العامة والإحصاء، نشرة إحصاءات التحات التجارة الخارجية، أعداد مختلفة. 
هشام علي \& 1 . 


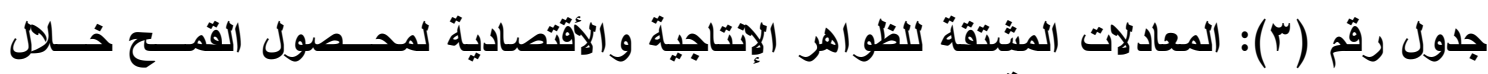

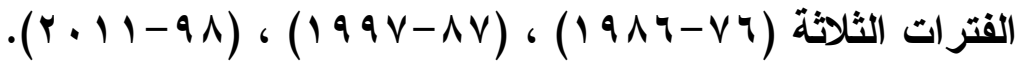

\begin{tabular}{|c|c|c|c|c|c|c|}
\hline معدل التغير & متوسط الفترة & التغير & المعادلة المشتقة & |الفترة & رقمعثة & الظاهرة \\
\hline $\begin{array}{l}1, \sum \wedge \\
r, \lambda \\
r, i v\end{array}$ & $\begin{array}{l}I r \cdot r \\
r \cdot r T, 0 \\
r V \cdot r, r\end{array}$ & $\begin{array}{l}19,4 r \\
V 7,91 \\
01,00\end{array}$ & 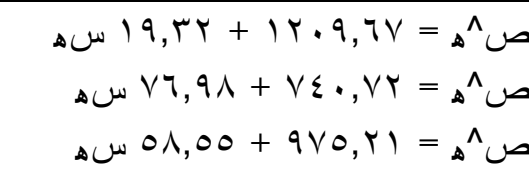 & الألثانية & $\begin{array}{l}1 \\
1 \\
r \\
r\end{array}$ & ألف فدانة \\
\hline $\begin{array}{l}1,1 \\
1,1 \wedge \\
\cdot, \cdot 5\end{array}$ & $\begin{array}{l}1, \leqslant 0 \\
r, 11 \\
r, 79\end{array}$ & $\begin{array}{l}\cdot,+17 \\
\cdot, \cdot \leq 1 \\
\cdot,+1\end{array}$ & 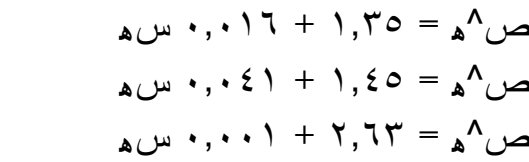 & الألثانية & $\begin{array}{l}\varepsilon \\
0 \\
1\end{array}$ & طن/فدان \\
\hline $\begin{array}{l}\varepsilon, r_{q} \\
0, r, T \\
r, r \varepsilon\end{array}$ & $\begin{array}{l}\text { I^qr } \\
\varepsilon \varepsilon r \neg, V \\
V Y \neg \vee, \varepsilon\end{array}$ & $\begin{array}{l}1,14 \\
r r 0,71 \\
179,97\end{array}$ & 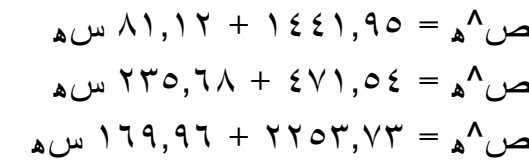 & الألثانية & $\begin{array}{l}v \\
\Lambda \\
q\end{array}$ & ألف طن \\
\hline $\begin{array}{l}11,70 \\
7, \leq 7 \\
1 \cdot, 7 \leq\end{array}$ & $\begin{array}{l}1 \cdot r \\
\varepsilon \wedge \varepsilon, r \\
|r| 1,9\end{array}$ & $\begin{array}{l}19, \cdot r \\
r 1,10 \\
1 \% \wedge, 9 V\end{array}$ & 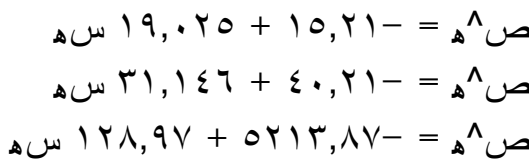 & الأولية الثالثة & $\begin{array}{l}10 \\
11 \\
11\end{array}$ & المزيهر/طني \\
\hline $\begin{array}{l}0, \varepsilon q \\
r, \varepsilon) \\
\varepsilon, \varepsilon\end{array}$ & $\begin{array}{l}0 r \leq r, V \\
\text { orr.,r } \\
0 \leq 7 r, 1\end{array}$ & $\begin{array}{l}\text { rAV, Q } \\
\text { MA, Ir } \\
r \varepsilon \cdot, r_{0}\end{array}$ & 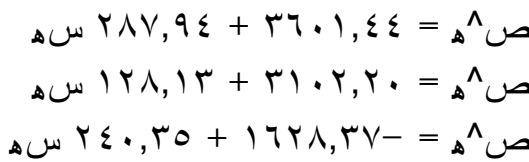 & الأولية الثالثية & $\begin{array}{l}14 \\
15\end{array}$ & ألو اردية \\
\hline $\begin{array}{l}0,01 \\
r, 9 \leq \\
r, 1 r\end{array}$ & $\begin{array}{l}\vee \backslash \wedge \vee, r \\
q \neg Y \cdot, \varepsilon \\
I Y \wedge \vee 0,1\end{array}$ & $\begin{array}{l}r 90, \wedge r \\
r V q, r V \\
\varepsilon \cdot 1, V V\end{array}$ & 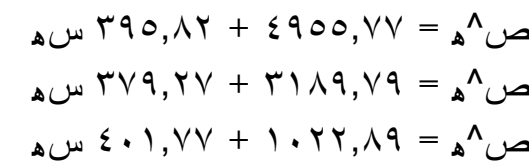 & الأولية & $\begin{array}{l}17 \\
17 \\
11\end{array}$ & لإلستهالاحك طن الإك طن \\
\hline
\end{tabular}

المصدر: حسبت من بيانات الجدول رقم (r).

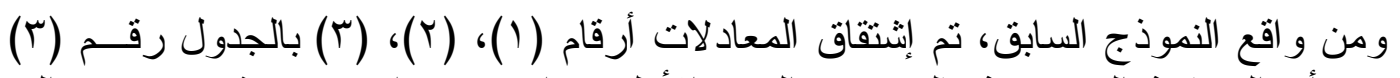

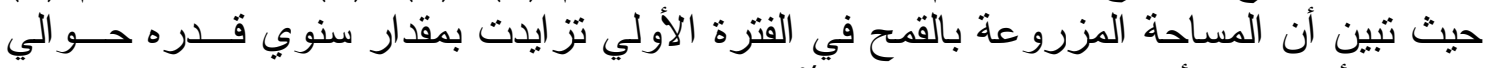

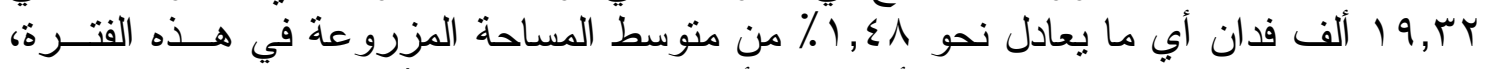

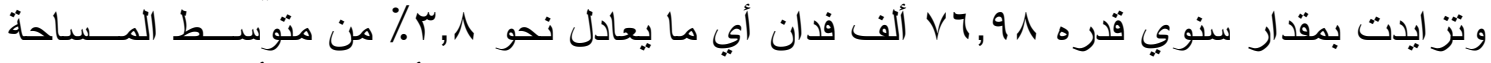

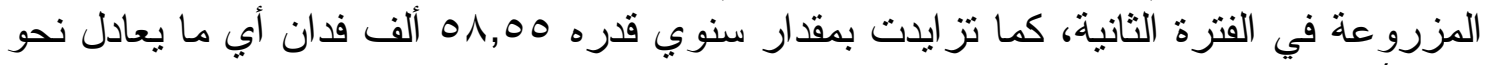

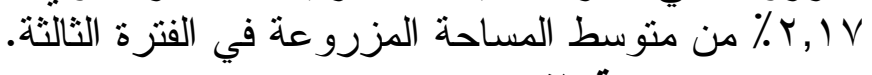

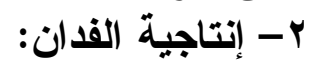

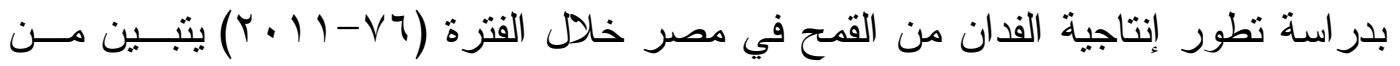

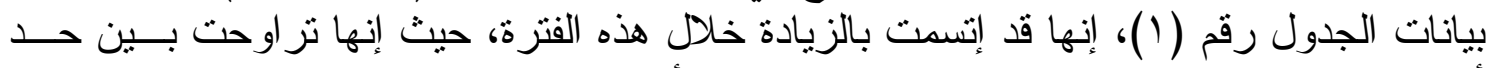

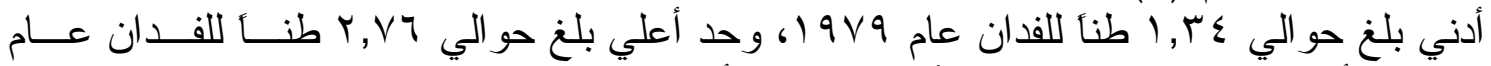

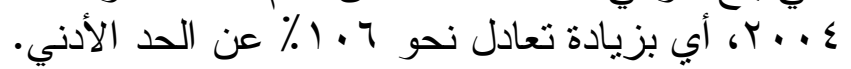

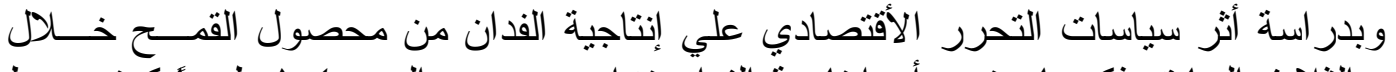

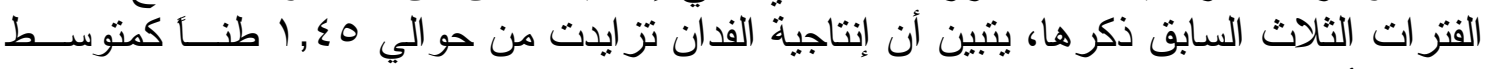

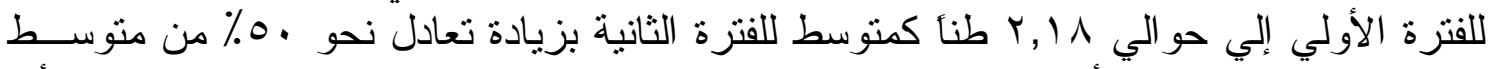

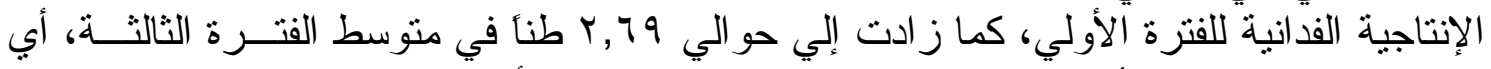

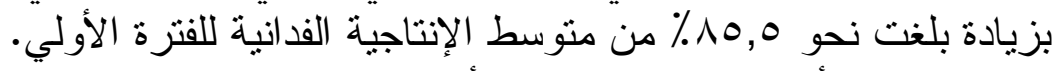

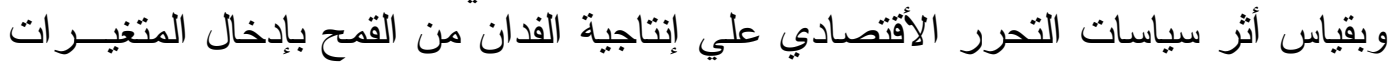

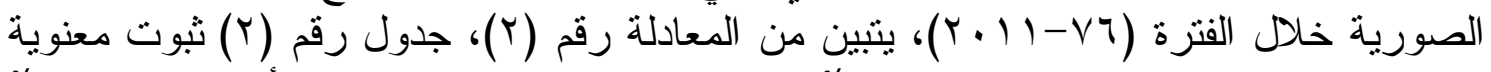

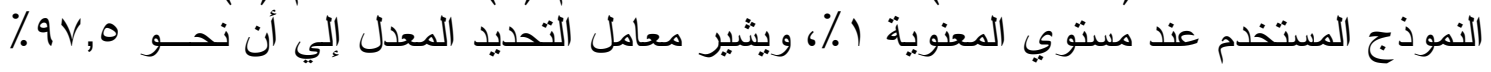




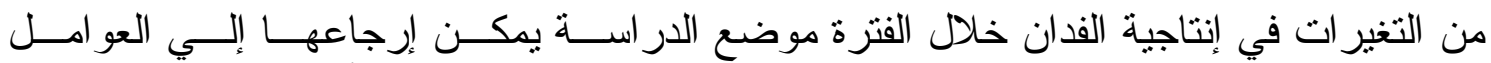

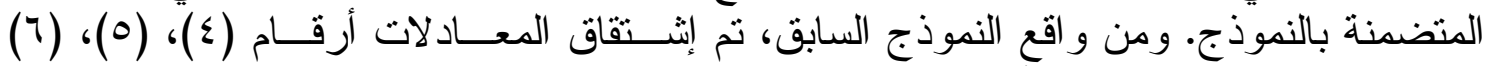

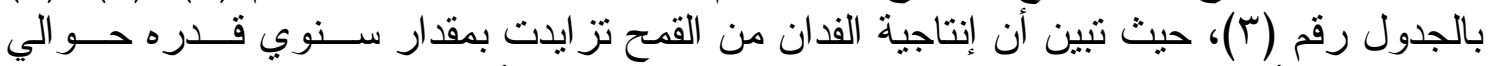

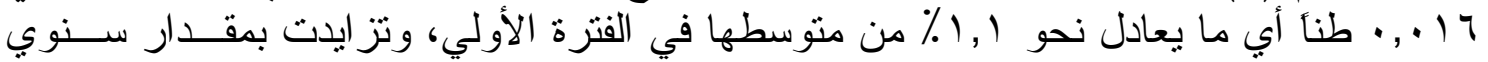

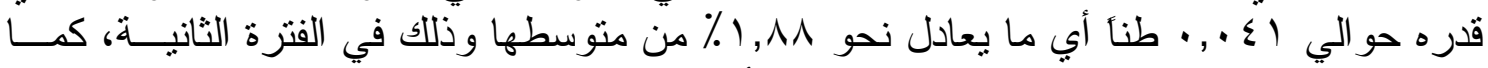

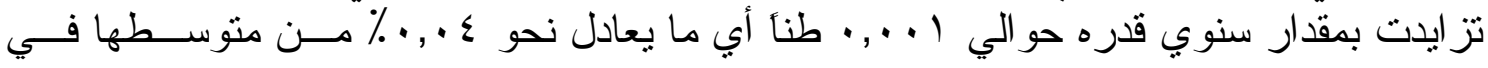
الفترة الثالثة.

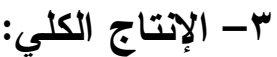

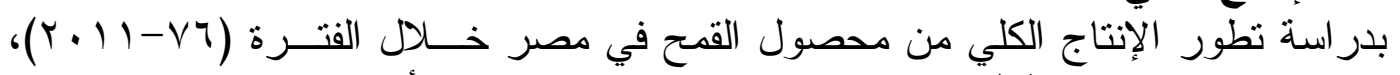

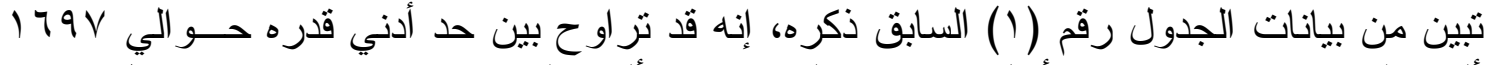

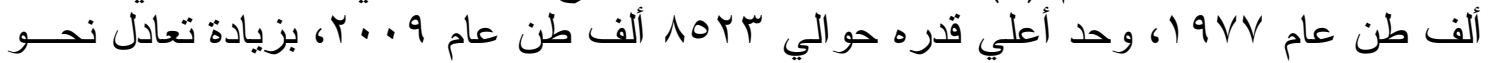

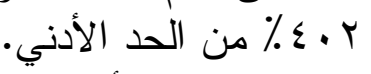

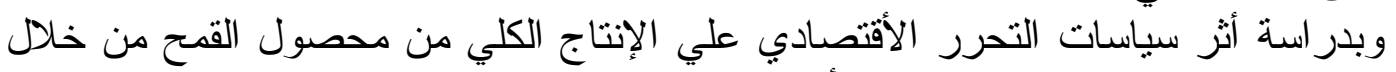

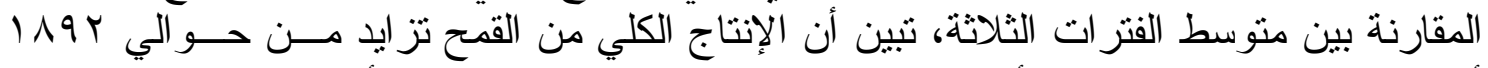

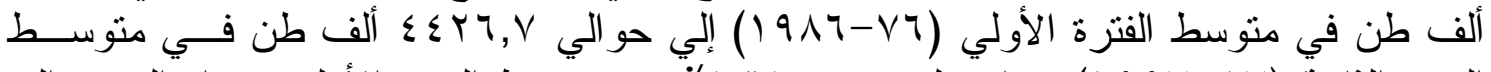

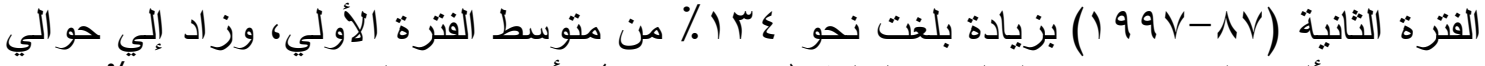

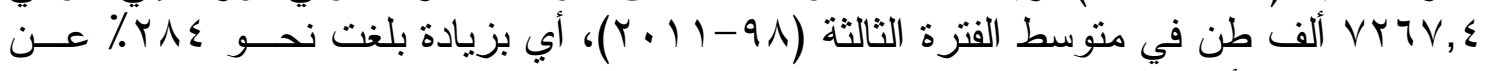
متوسط الفترة الأولي.

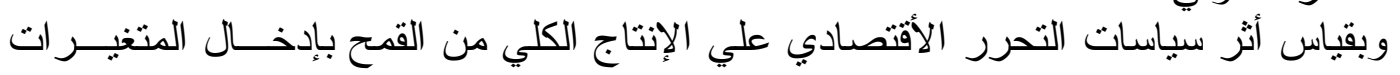

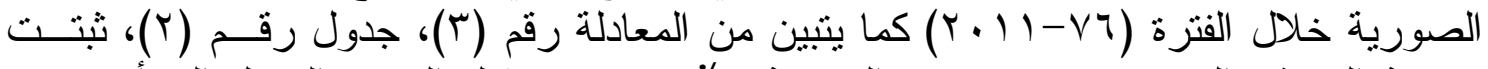

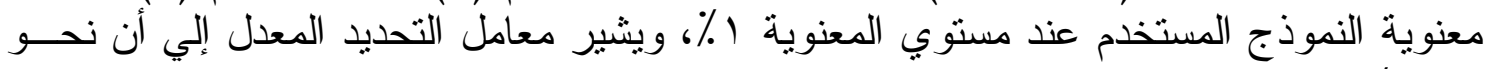

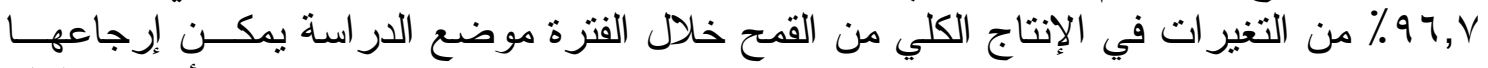

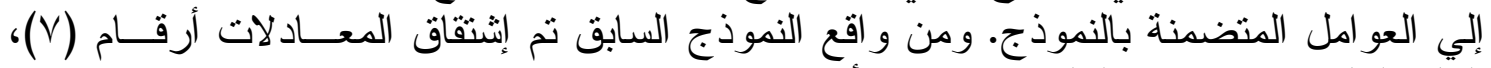

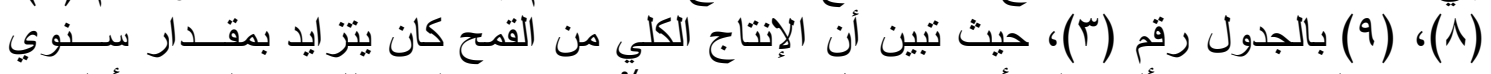

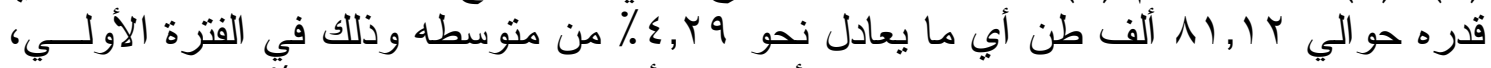

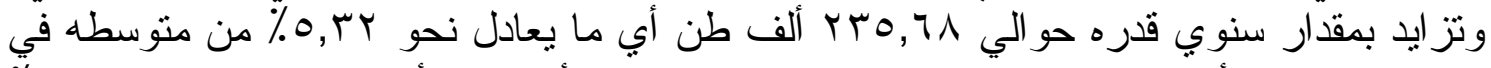

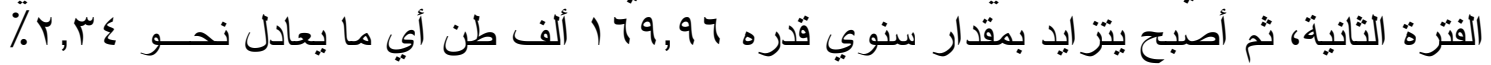
من منوسطه في الفترة الثالثة. ع - السعر المزرعي:

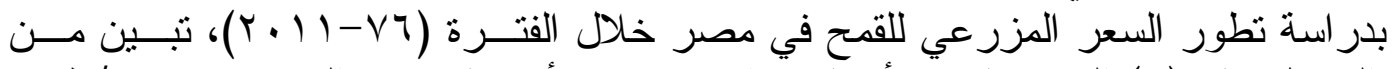

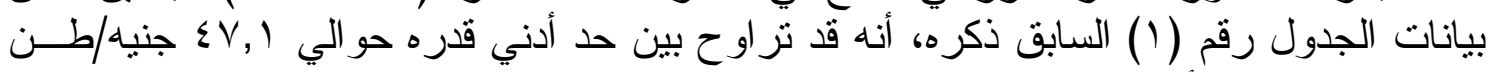

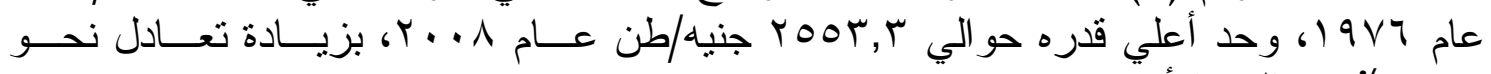

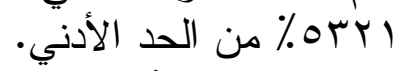

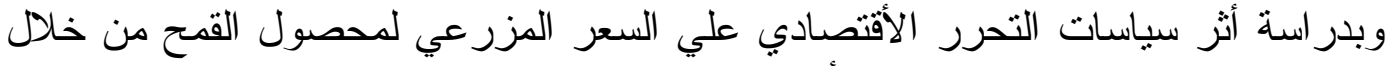

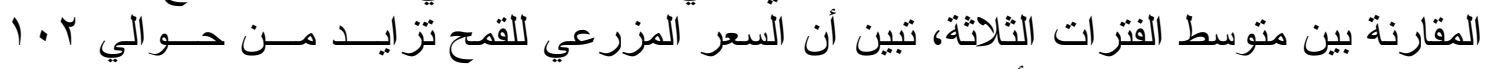

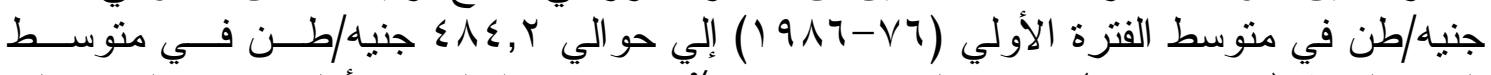

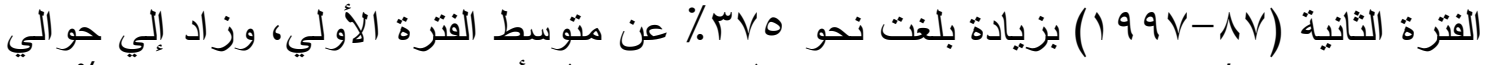

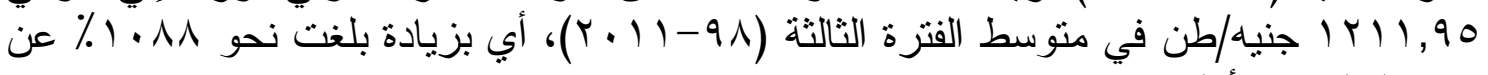
متوسط الفترة الأولي.

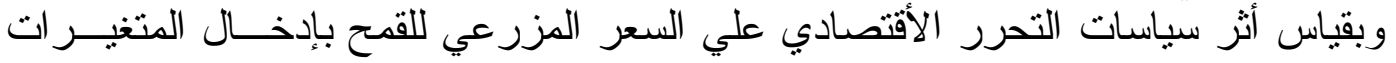

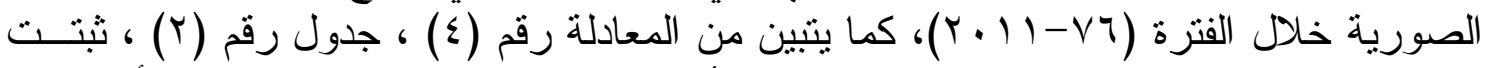

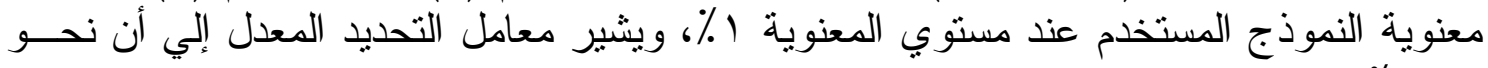

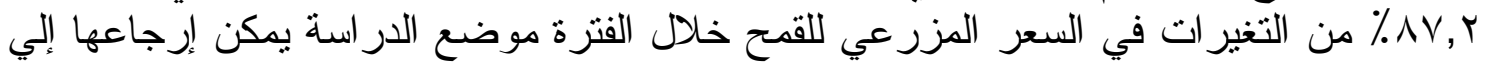




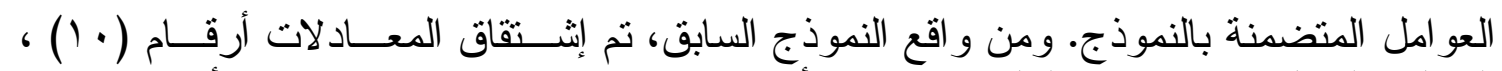

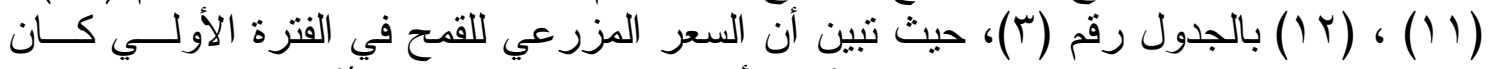

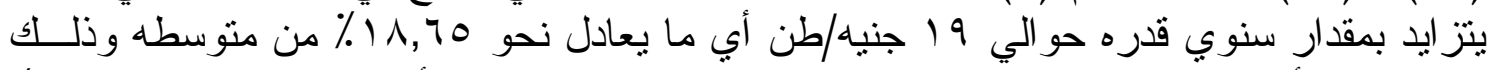

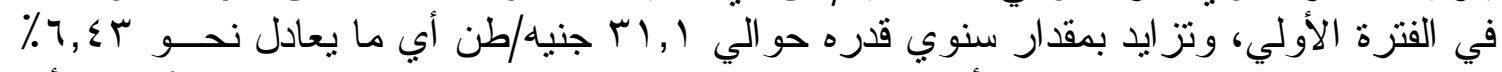

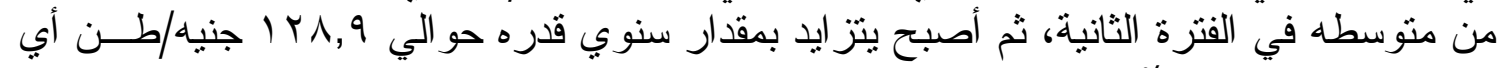

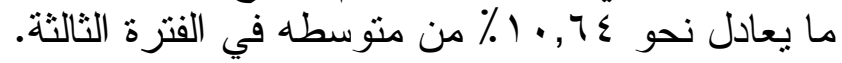

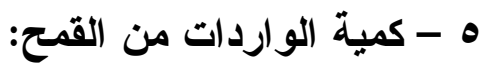

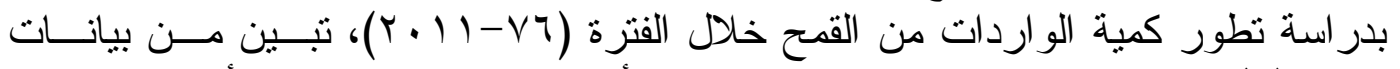

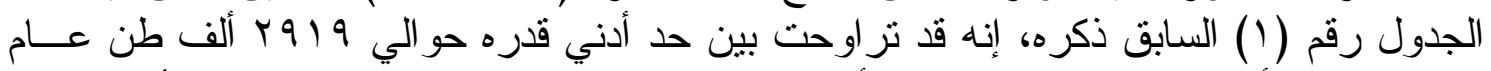

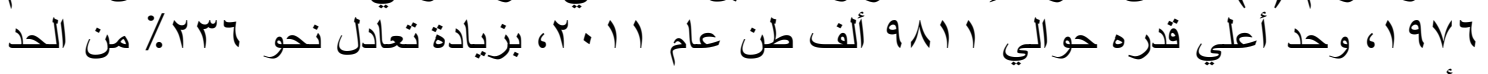

وبقياس أثز سياسات التحرر الأقتصادي علي كمية الواردات من القمح خلال المقارنة بين الأدني.

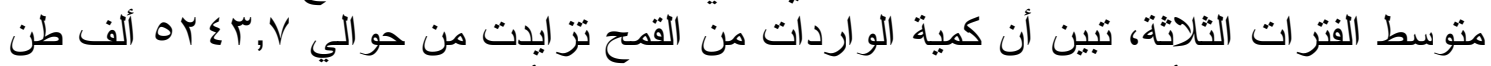

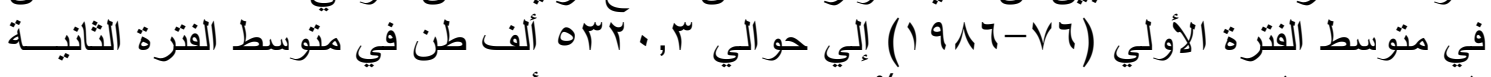

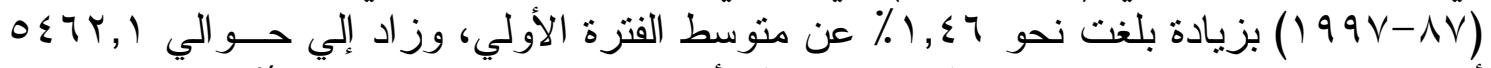

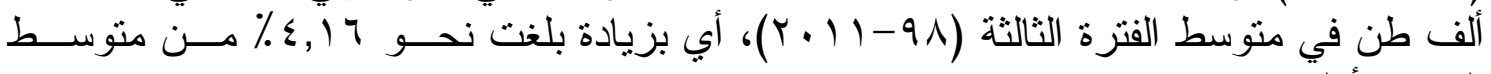

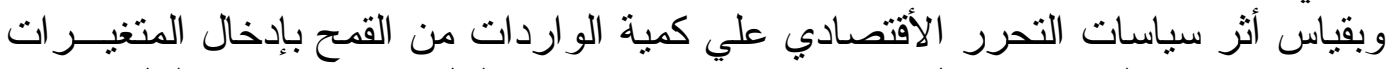

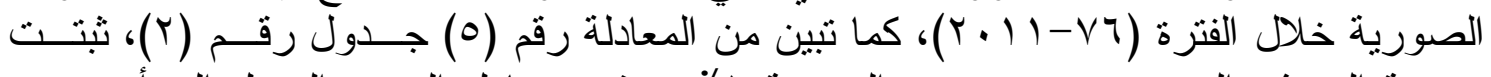

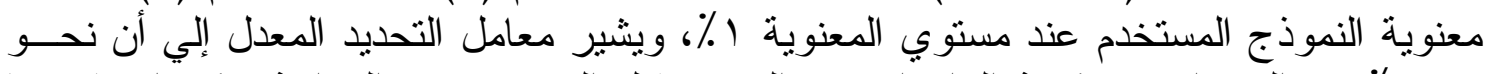

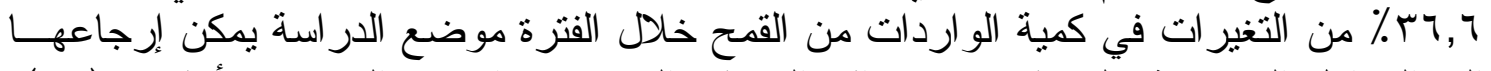

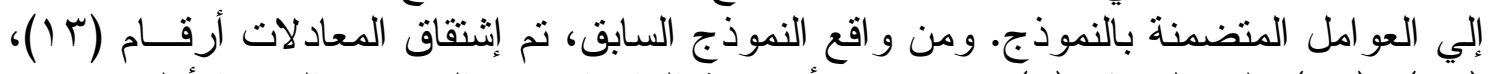

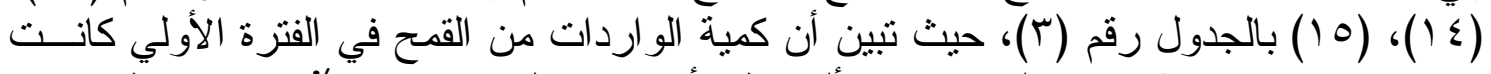

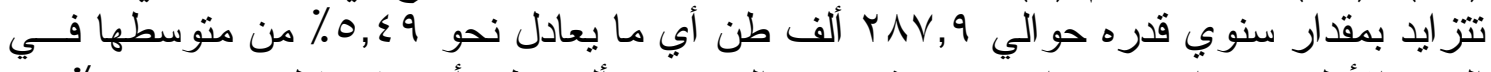

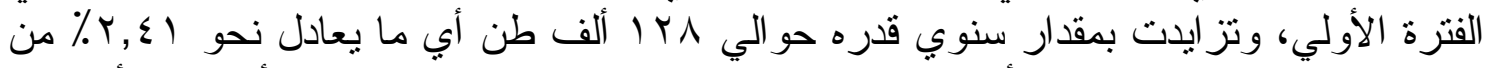

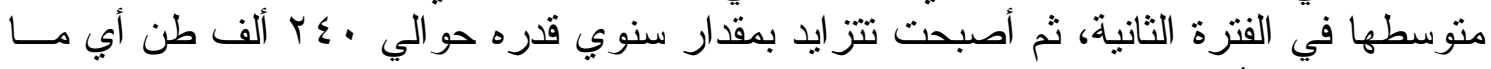

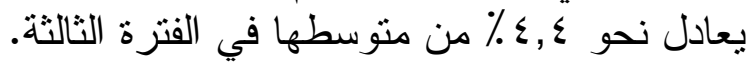

צ- كمية المتاح للإستهلاك من من القمبح:

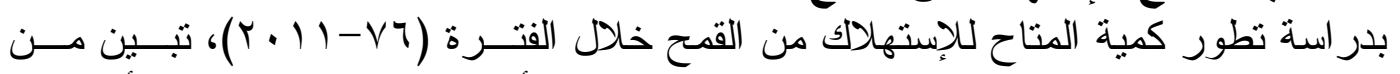

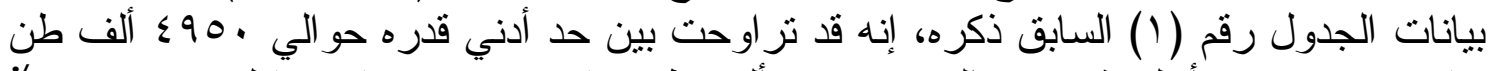

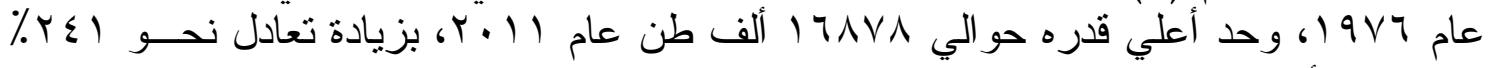

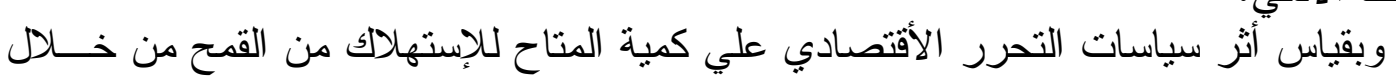

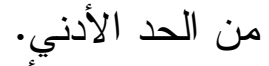

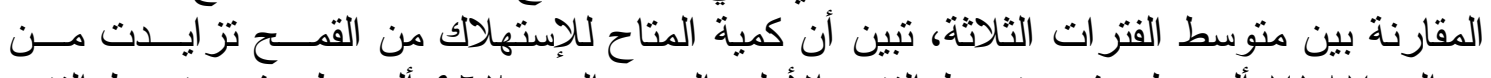

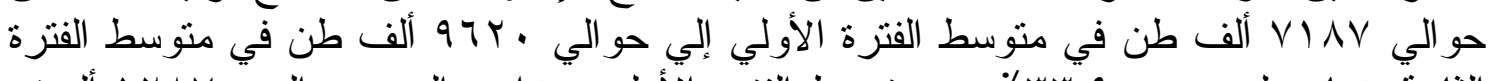

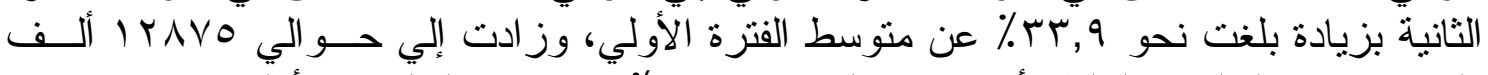

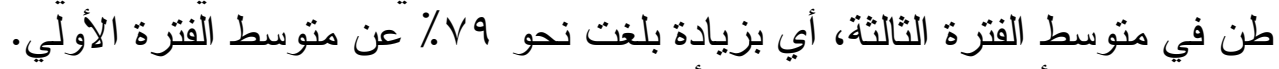

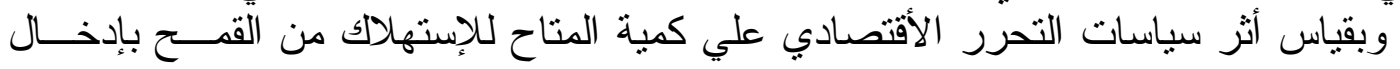

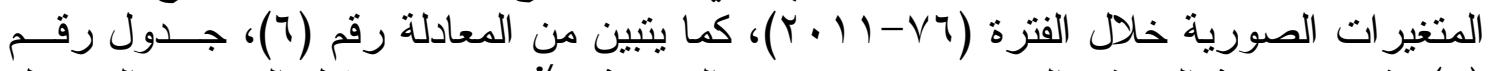

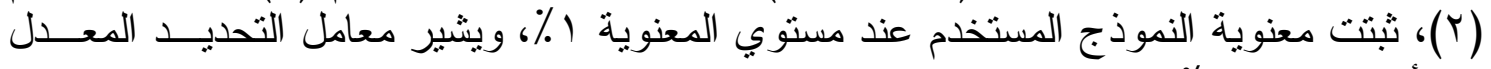

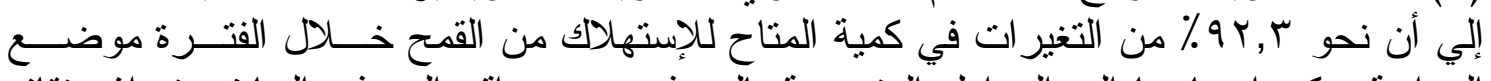

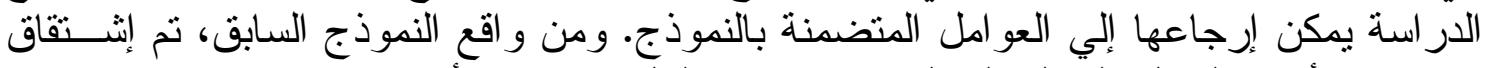

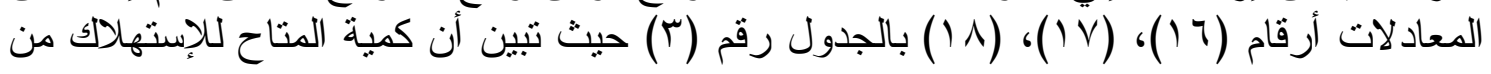




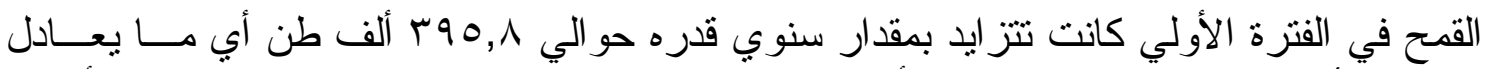

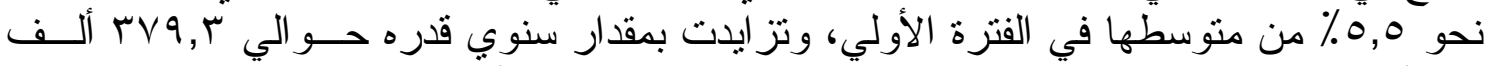

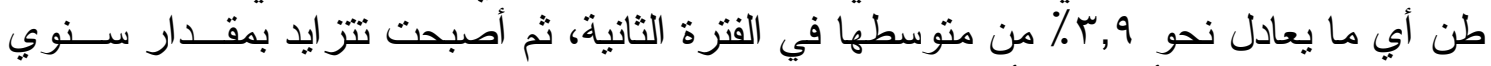

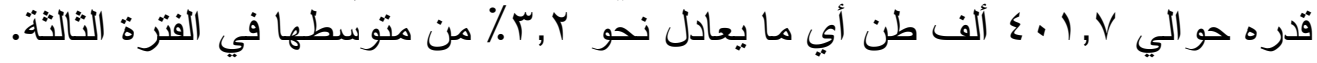

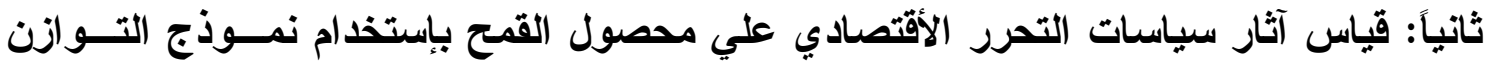

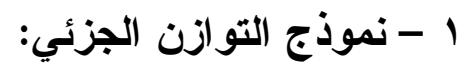

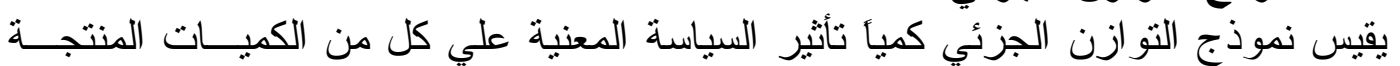

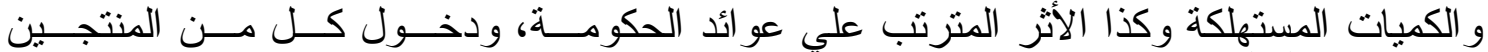

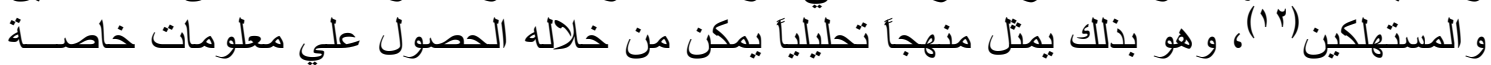

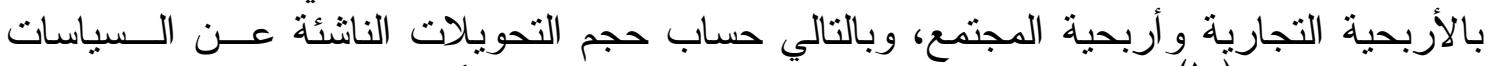

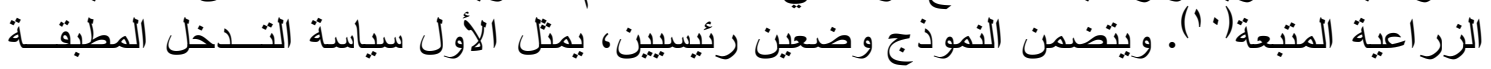

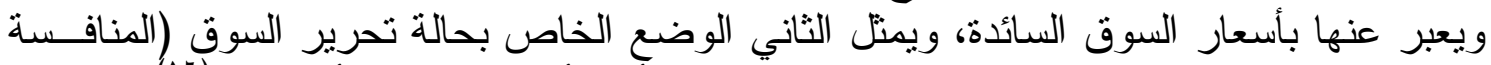

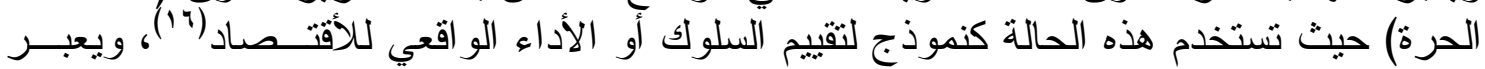

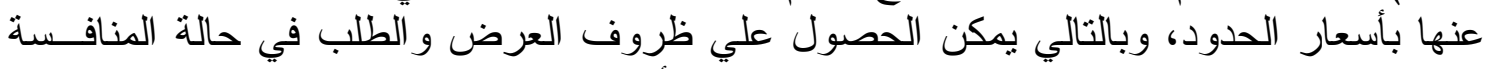

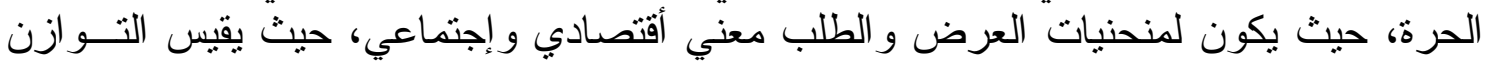

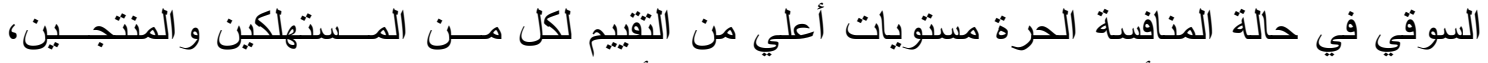

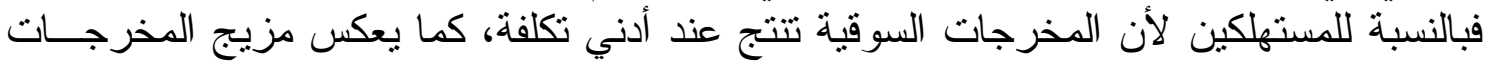

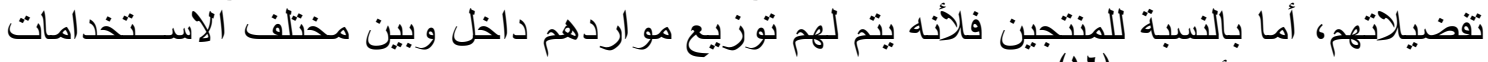

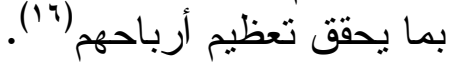

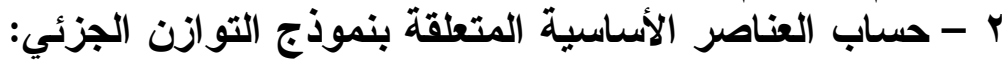

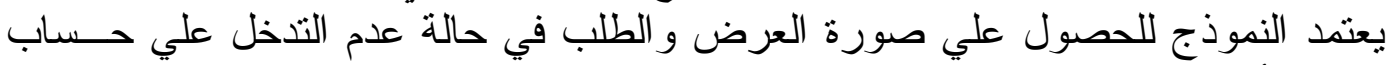
ثلاثة عناصر أساسية بيانها كالتالي: لإني

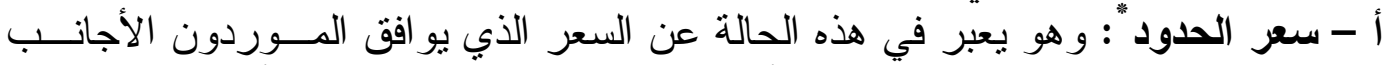

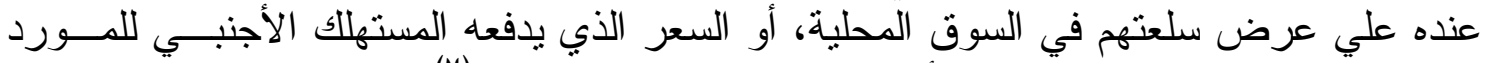

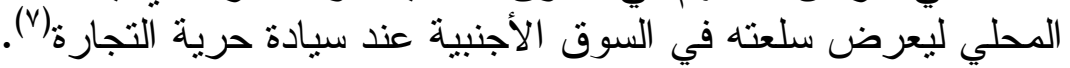

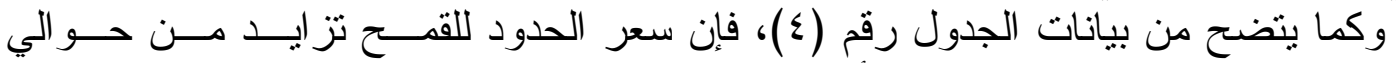

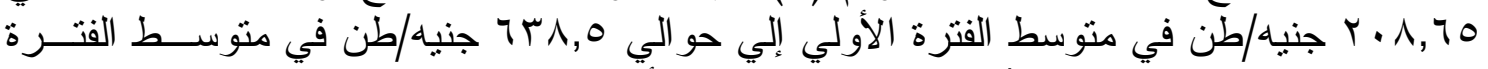

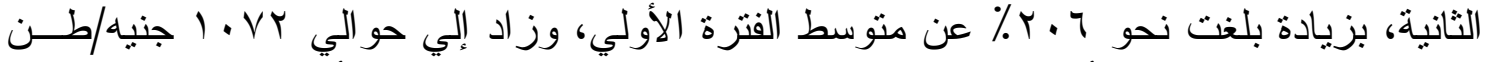

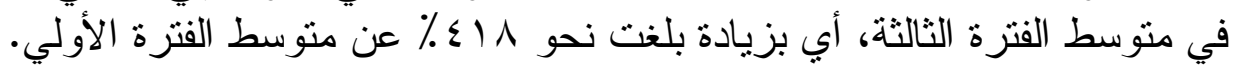

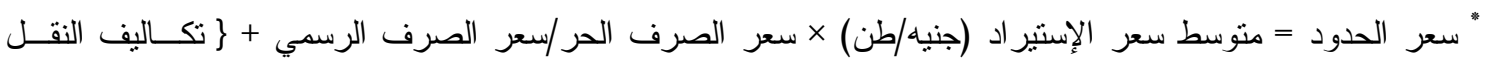

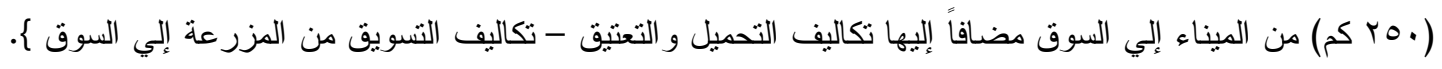




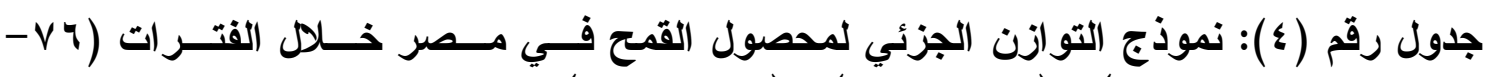

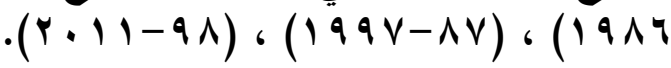

\begin{tabular}{|c|c|c|c|c|}
\hline متوسط الفترة الثالثة & 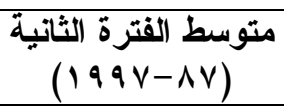 & 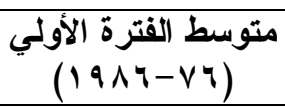 & الوحدة & البيان \\
\hline & & & & المؤشرات عند الوضع القائم \\
\hline VYTV, & $\varepsilon \varepsilon r \neg, V$ & $1 \wedge 9 r$ & ألف طن & الإنتاج \\
\hline $0 \leq 7 Y, 1$ & Orr.,r & Or $\leqslant r, V$ & ألف طن & الو اردات \\
\hline TKVYq,0 & $9 \vee \leqslant V$ & $V \backslash T_{0, V}$ & ألف طن & الإستهلاك \\
\hline $1,11,9$ & $\varepsilon \wedge \varepsilon, r$ & $1 \cdot r$ & جنيه/طن & السعر المزرعي \\
\hline $17 V V, 0$ & $V \varepsilon \cdot, V V$ & $1 \leqslant 0, r$ & جنيه/طن & سعر المستهلك \\
\hline $1 \cdot V Y$ & $7 \mu \wedge, 01$ & $r \cdot \Lambda, 70$ & جنيه/طن & سعر الحدود \\
\hline $1,1 \pi$ & $\cdot, \vee \vee T$ & $\cdot, \leqslant 9$ & - & معامل الحماية الأسمي للمنتجات \\
\hline 1,07 & 1,17 & $\cdot, \mathrm{V} \cdot$ & - & معامل الحماية الأسمي للمستهلك \\
\hline$\cdot, r \mu$ & $\cdot, r q$ & $\cdot, Y T$ & - & مرونة العرض \\
\hline$\cdot, r \leqslant-$ & $\cdot, 9 \varepsilon-$ & 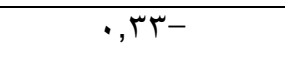 & - & مرونة الطلب \\
\hline $11,0 .-$ & M, $1,0 \Lambda$ & $1 \cdot \varepsilon, 1$ & $\%$ & المزرعي للفرق بين سعر الحدود و السعر \\
\hline ro,9.- & $1 \%, \vee 9-$ & $\sum Y, \wedge Y$ & $\%$ & \% للفرق بين سعر الحدود وسعر \\
\hline I9Y,YY- & $0 \leqslant 0, Y$. & 011,99 & ألف طن & كمية التغير في الإنتاج* \\
\hline $100 \%, \vee 7$ & 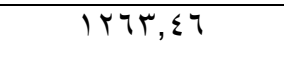 & $1 \cdots 9, Y 7-$ & ألف طن & كمية التغير في الإستهلاك ** \\
\hline & & & & المؤشر ات عند وضع عدم التدخل: \\
\hline$V \cdot V 0,1 \wedge$ & $\varepsilon 9 \vee 1,9$ & $r \varepsilon \cdot r, q 9$ & ألف طن & الإنتاج \\
\hline$\checkmark Y \cdot \Lambda, \cdot \Lambda$ & $7 \cdot T \wedge, 07$ & MVYY, ¿0 & ألف طن & الو اردات \\
\hline IEYAT,YT & $11 \cdot 1 \cdot, \leqslant 7$ & オイ,$\varepsilon \varepsilon$ & ألف طن & الإستهلاك \\
\hline
\end{tabular}

* كمية التغير في الإنتاج = ٪ للفرق بين سعر الحدود و السعر المزرعي × مرونة العرض × الإنتاج الفعلي.

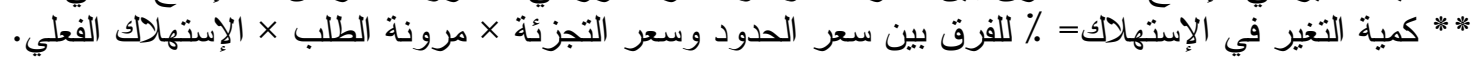

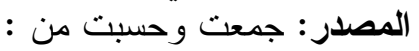

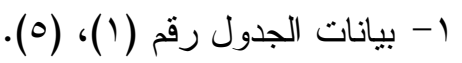

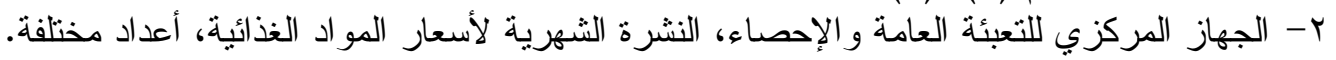

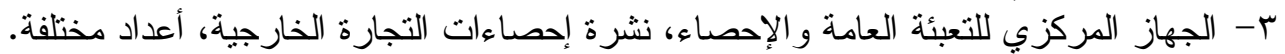

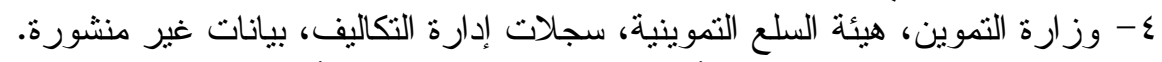

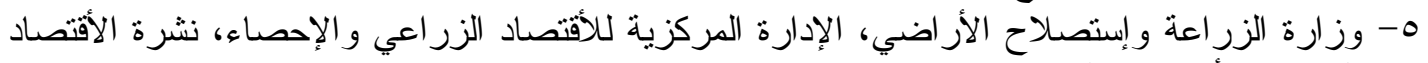
الزر اعي، أعداد مختلفة.

\section{ب - معاملات الحماية الأسمية للمنتجات و المستهلك:}

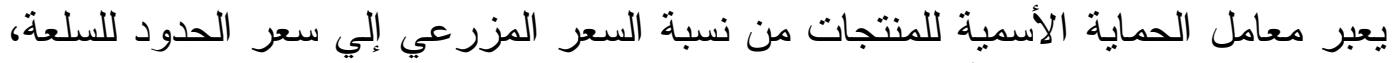

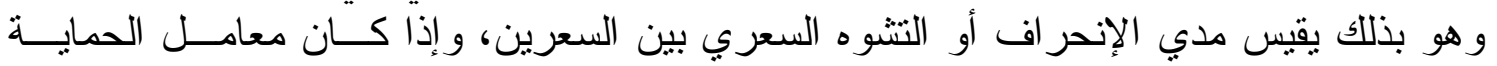




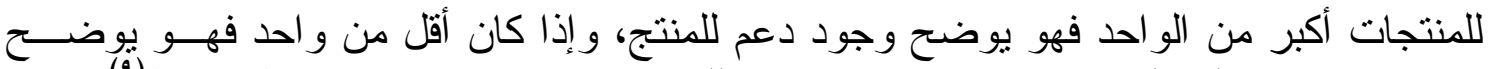

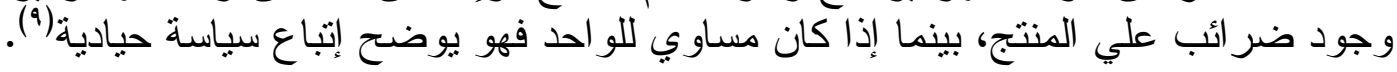

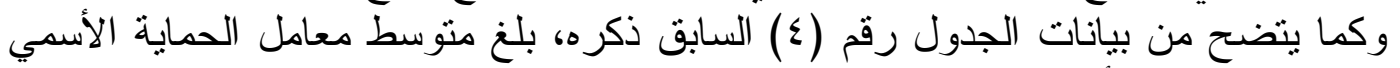

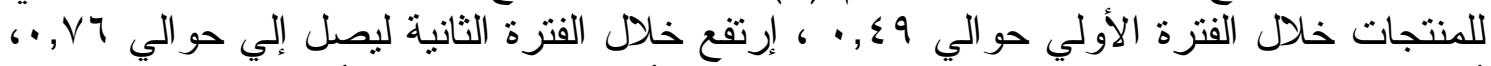

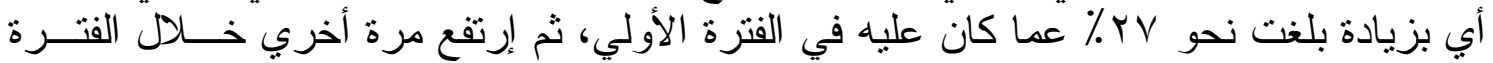

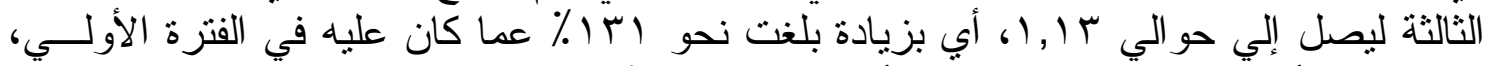

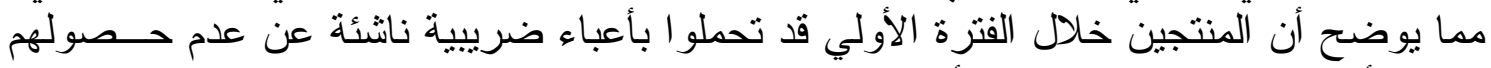

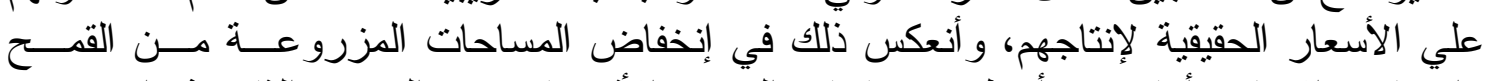

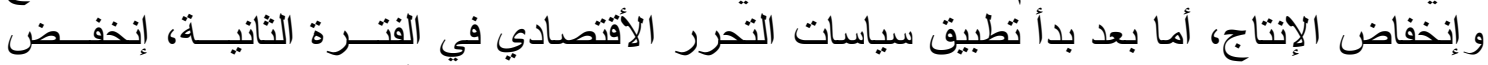

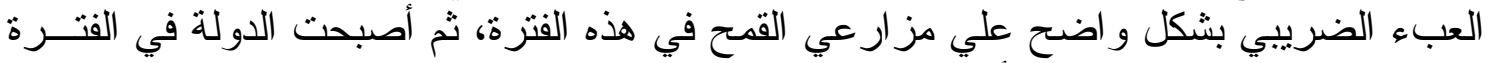

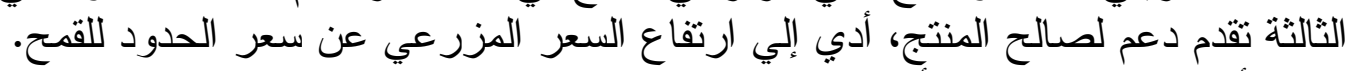

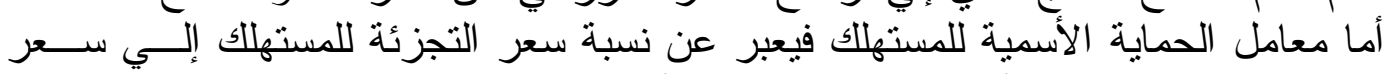

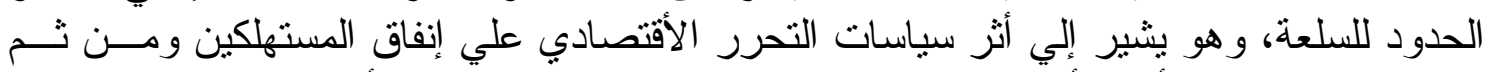

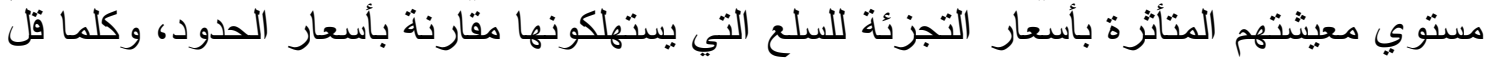

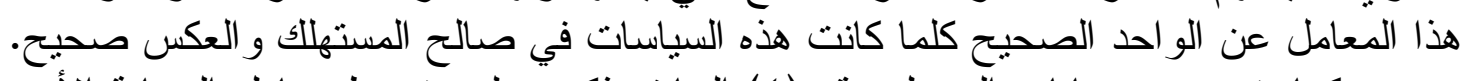

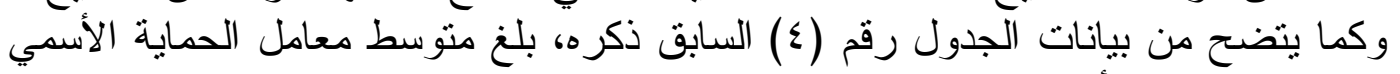

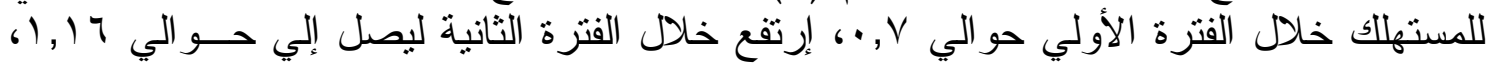

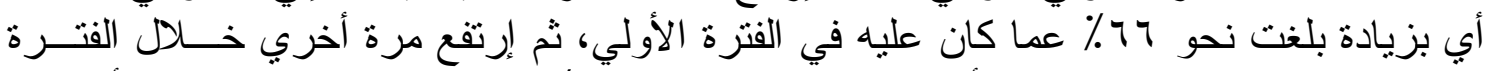

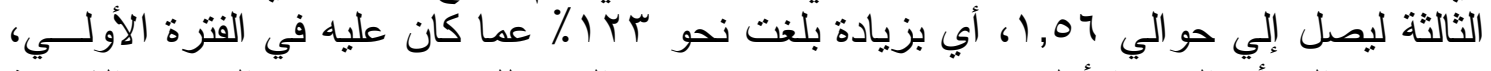

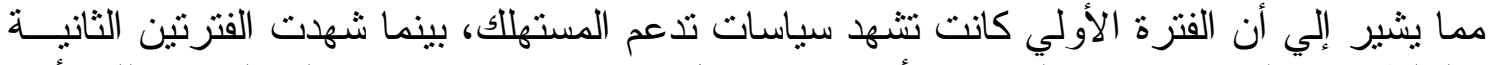

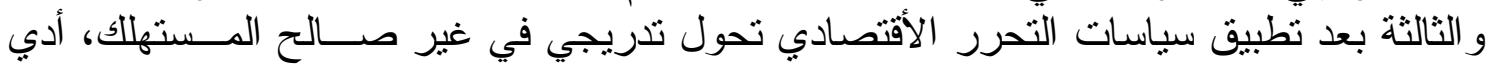

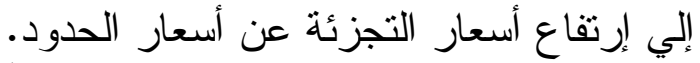

$$
\begin{aligned}
& \text { ج - مرونات العرض و الطلب السعرية: }
\end{aligned}
$$

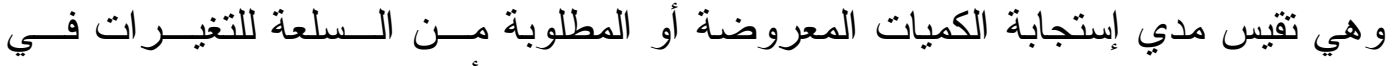

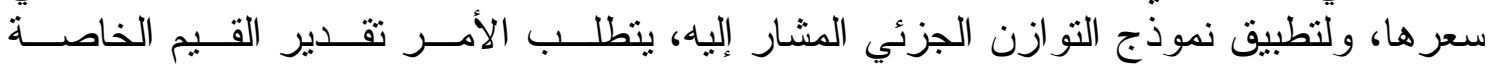

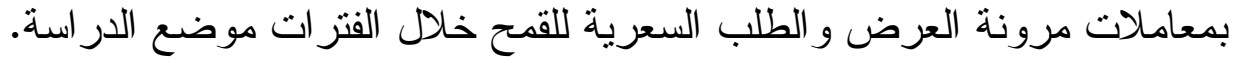

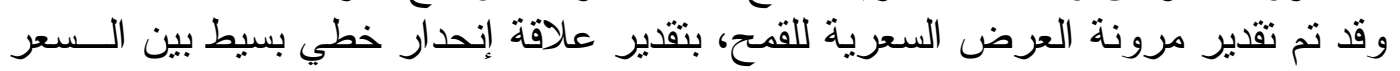

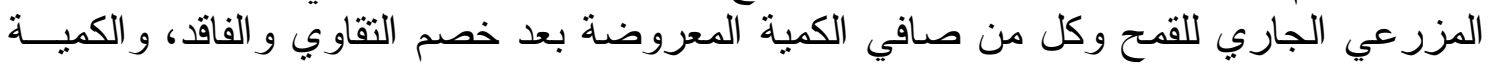

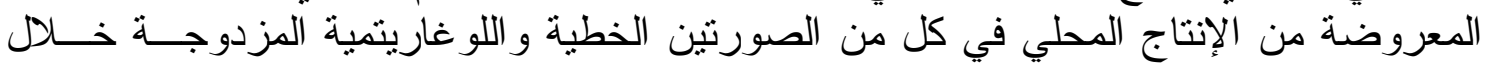

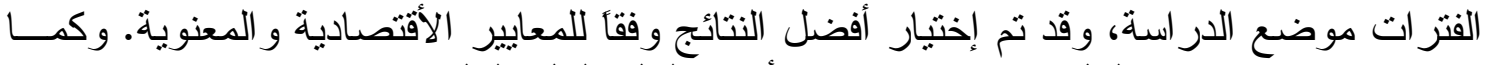

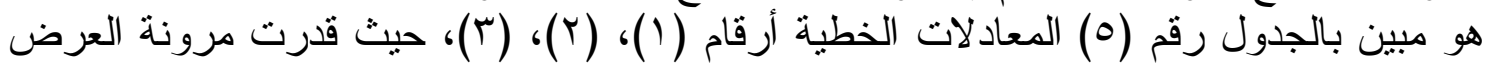

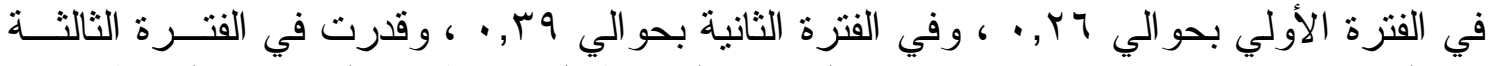
بحو الي بr , •، ورهي قيم تثتفق مع مرونات العرض الفي السعرية المحسوبة من الدر استات السابقة.

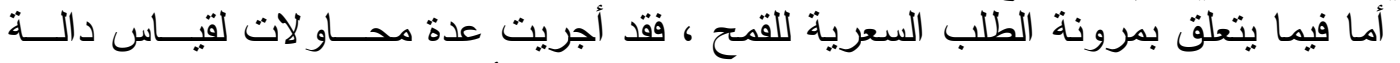

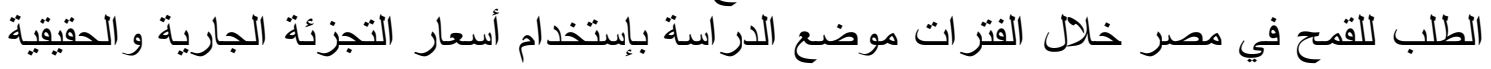

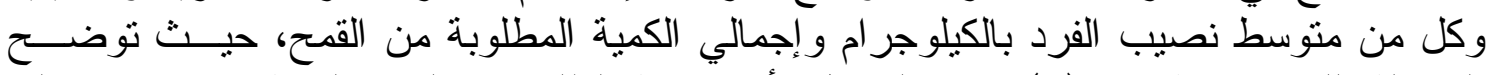

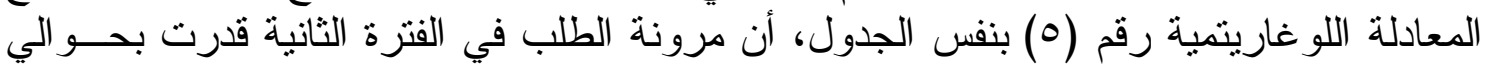

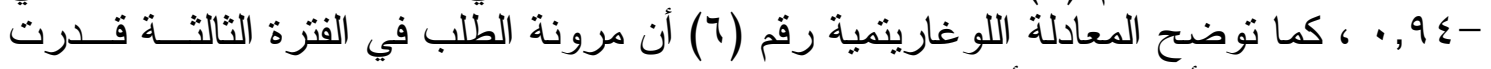

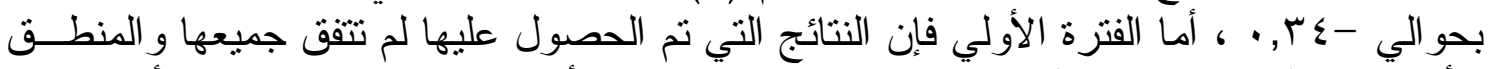
الأقتصادي (المعادلة رقم ع)، مما يشير إلي وجود عو امل أخري بجانب السعر يمكن أن تفـسر

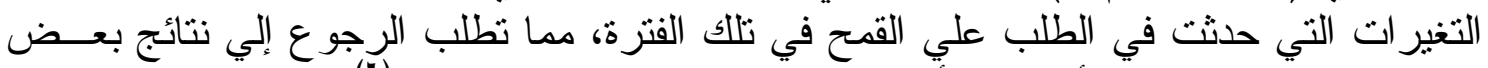

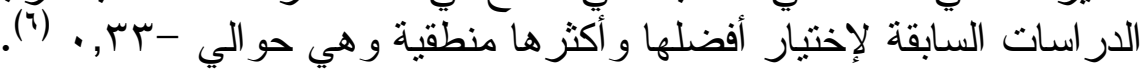


وفي ضوء ذللك يتم حساب التخير في الإنتاج و الإستهالك في حالة عدم التذخل علي النحو

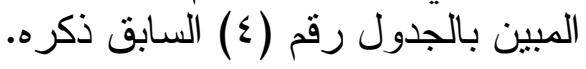

جدول رقم (0): معادلات الإحدار الخطي البسيط بين السعر المزرعي وسعر التجزئة وكل مــن

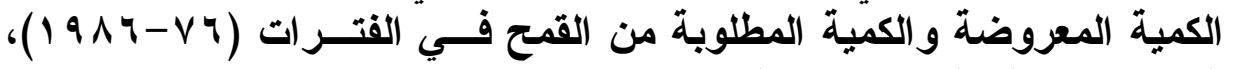

\begin{tabular}{|c|c|c|c|c|c|c|c|}
\hline \multicolumn{8}{|c|}{.$(r \cdot 11-9 \Lambda) \cdot(199 \vee-\Lambda \vee)$} \\
\hline 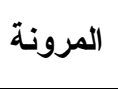 & ف & $r-\jmath$ & r & المعادلة & 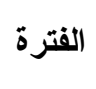 & المرونة & 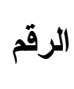 \\
\hline$\cdot, r 4$ & $* \vee, 1 \varepsilon$ & $\cdot, \uparrow \wedge$. & $\cdot$, - $\leqslant \leqslant\}$ & 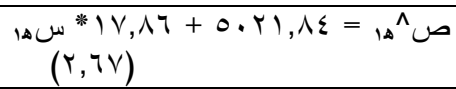 & الأولي & 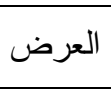 & 1 \\
\hline$\cdot, r q$ & $* * 1 \leqslant, \uparrow \uparrow$ & $\cdot, 0 \vee \wedge$ & $\cdot, \pi$. & 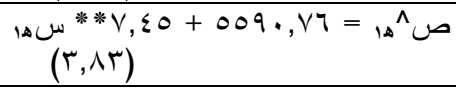 & 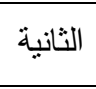 & & $r$ \\
\hline$\cdot, r T$ & $* * \mid \wedge, \vee r$ & $\cdot$, OVY & $\cdot, 71 \cdot$ & 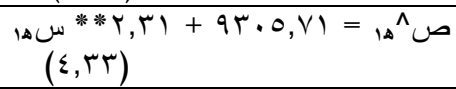 & الثالثة & & $r$ \\
\hline- & $* 1 \cdot, \cdot 1$ & $\cdot, \sum \vee 7$ & $\cdot, 0$, & 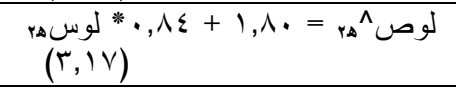 & 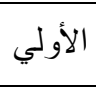 & 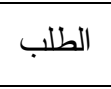 & $\varepsilon$ \\
\hline$\cdot, 9 \leq-$ & $* 0, Y \wedge$ & $\cdot, r 99$ & $\cdot, r V \cdot$ & 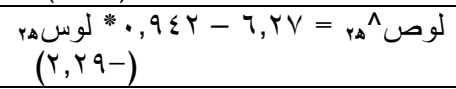 & الثانية & & 0 \\
\hline$\cdot, \Gamma \leq-$ & $* 0,19$ & • TYY & • r rVo & 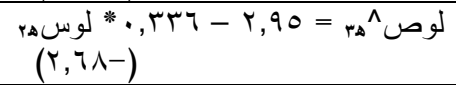 & الثالثة & & 7 \\
\hline
\end{tabular}

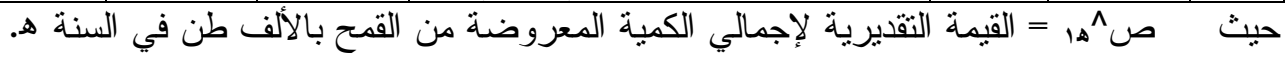

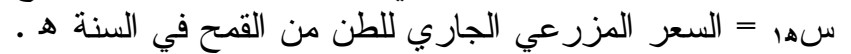

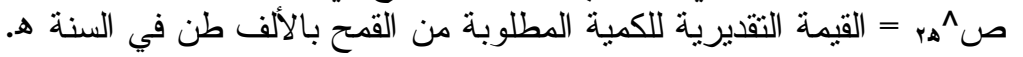

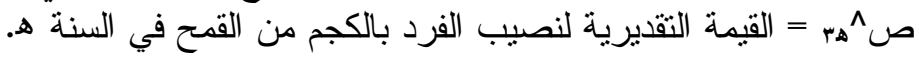

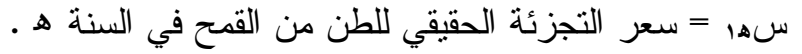

المصدر: حسبت من:

ا- وزارة الزر اعة وإستصلاح الأراضي، الإدارة المركزية للأفتصاد الزراعي و الإحصاء، نشرة الأقتصاد الزر اعي، أعداد مختلفة.

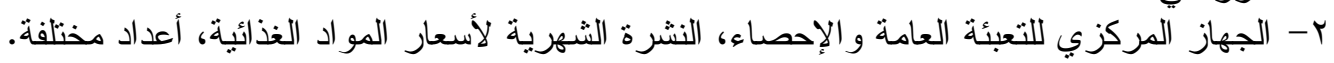

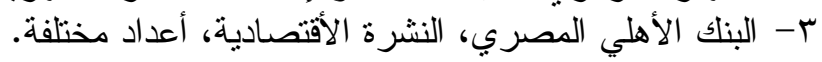

ع - بيانات الجدول رقم (1) (1).

ب - نتائج تطبيق نموذج التوازن الجزئي لمحصول القمح خلان الفترات موضع الدراسة:

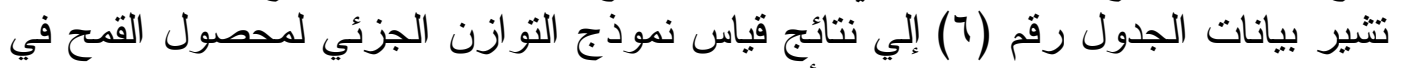
مصر خلال الفتر ات موضع الدر اسة، حيث أمكن التوصل إلت إلي النتائج التالية:

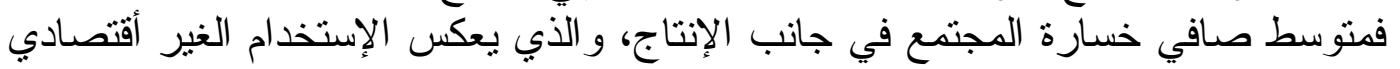

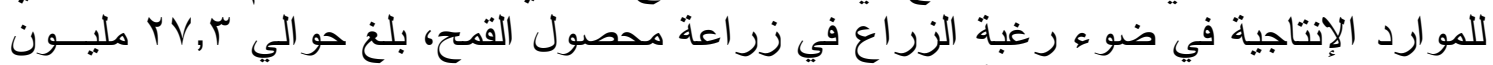

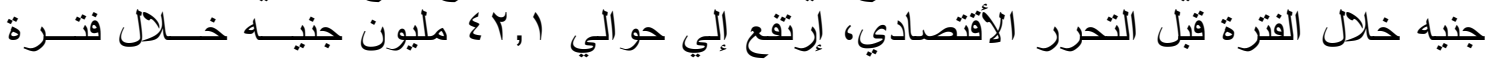

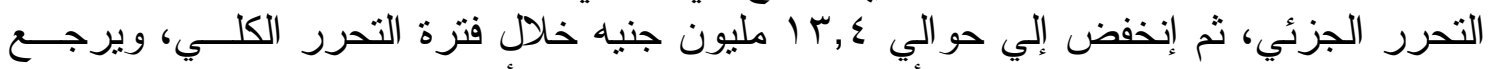

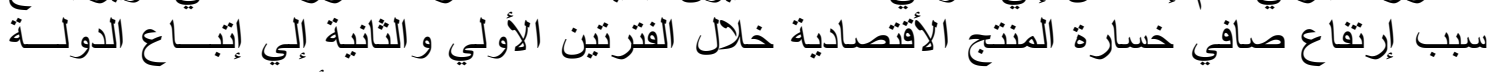

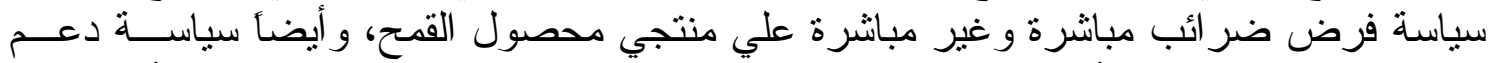

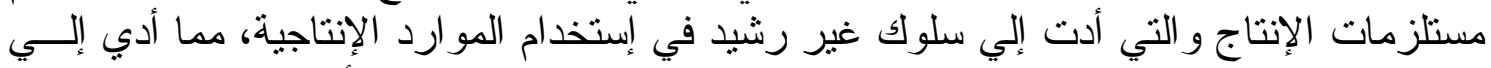

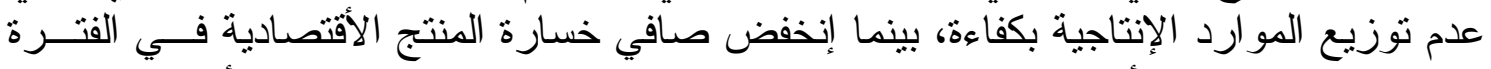

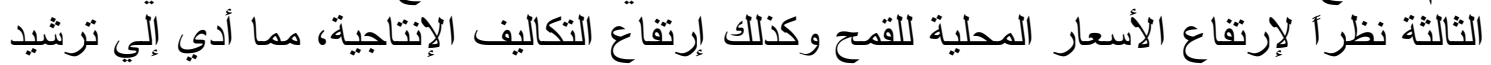

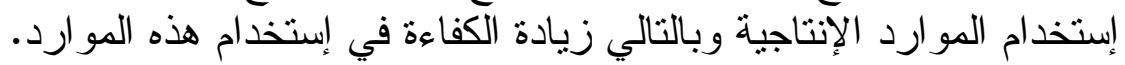

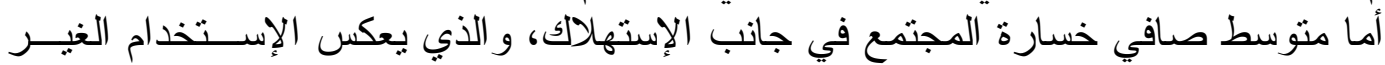

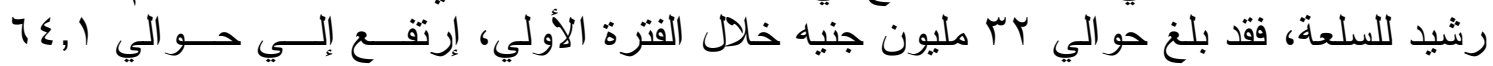

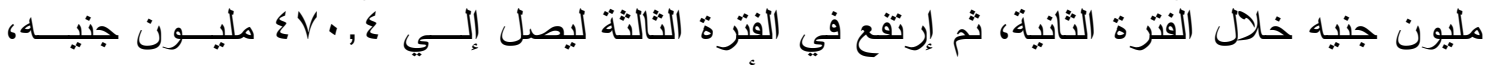

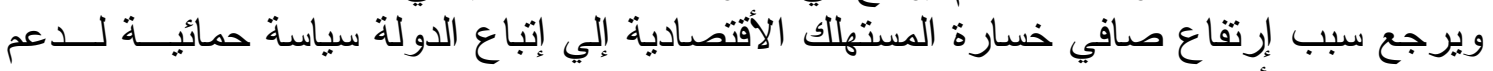
المستهلك مما أدي إلي حالة من سوء توزيع الإنفاق الإستهالَكي. 


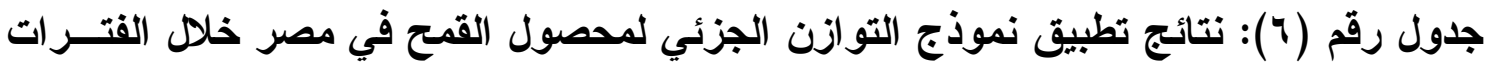

\begin{tabular}{|c|c|c|c|c|}
\hline 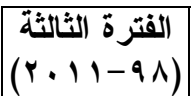 & 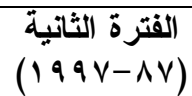 & (القترة الأولي & الوحدة & معالم النموذج \\
\hline $1 \%, \varepsilon \leqslant 7$ & $\sum Y, \cdot 70$ & $\langle V, r \cdot r$ & مليون جنيه & NSLP صافي خسارة المجتمع في جانب الإنتاج \\
\hline$\varepsilon V \cdot, \xi \cdot 1$ & $7 \varepsilon, 7 \cdot 1$ & $r, 97 \wedge$ & مليون جنيه & صLافي خسارة المجتمع في جانب الإستهلاك \\
\hline$\varepsilon \wedge \Upsilon, \wedge \varepsilon \vee$ & $1 \cdot 7,777$ & $09, Y V \cdot$ & مليون جنيه & جملة صافي خسارة المجتمع NSL \\
\hline 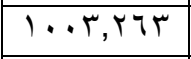 & $V Y 0,1 \leq 9-$ & rYq,・^乏- & مليون جنيه & GP عو ائد الرفاهية للمنتجين \\
\hline 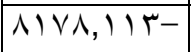 & $1.71, r Y q-$ & $\varepsilon r \cdot, \cdot \vee q$ & مليون جنيه & G ع ائد الرفاهية للمستهلكين \\
\hline $7791, \ldots r$ & $17 V 9, \wedge 1 Y$ & YO.,YTO- & مليون جنيه & التغير في إير اد الحكومة dG \\
\hline$|\wedge \vee 1,79|$ & $\{0 \Lambda, 7)\rceil$ & rIV,乏.q- & مليون جنيه & التغير في حصيلة النقد الأجنبي dF \\
\hline$\varepsilon \wedge$ & $1 \cdot 7,777-$ & $09, Y \vee \cdot-$ & مليون جنيه & صافي الآثر علي الواردات NETE \\
\hline
\end{tabular}

المصدر : جمعت وحسبت من بيانات الجدول رقم (0).

وبتقدير التغير في رفاهية كل من المنتج والمستهلك لبيان الآثار الإيجابية و السلبية لسياسة التيات

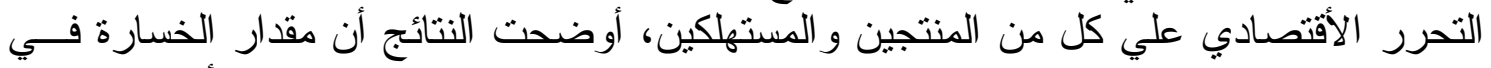

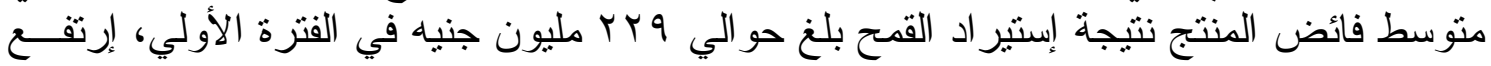

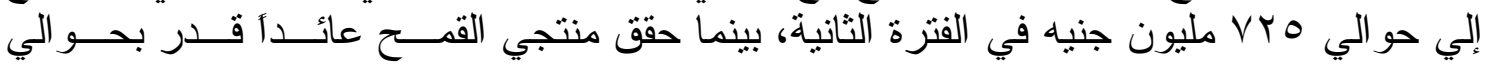

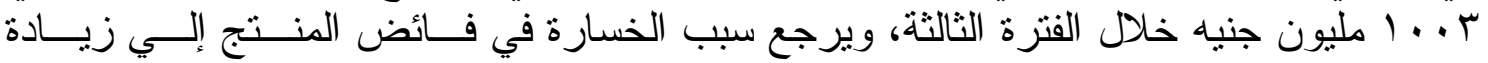

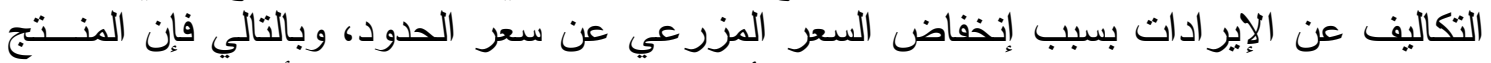

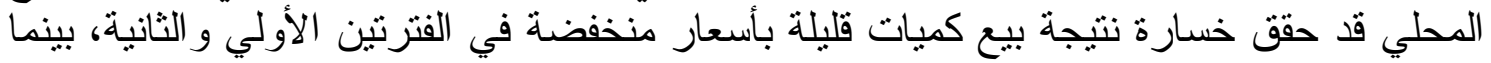

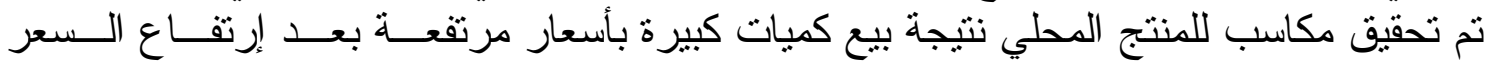

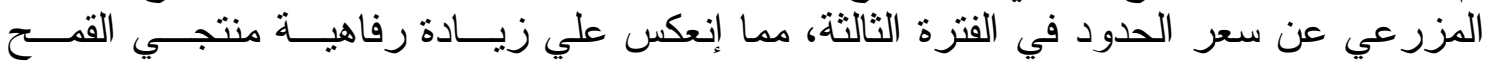
وتضاؤل حجم الفجوة الغذائية نسبيأ في هذه الفترة.

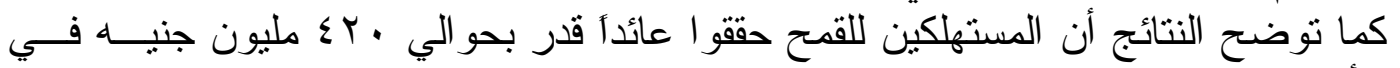

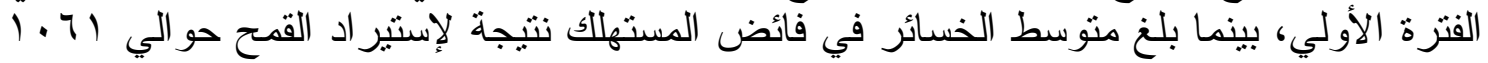

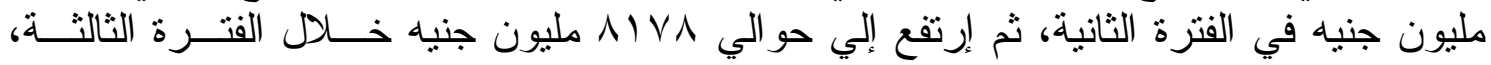

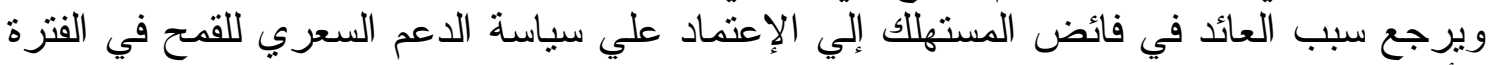

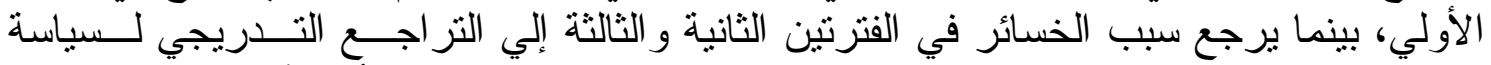

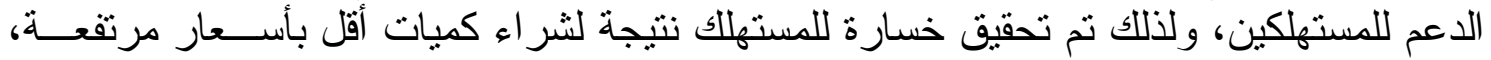

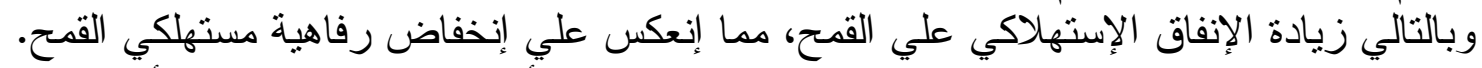

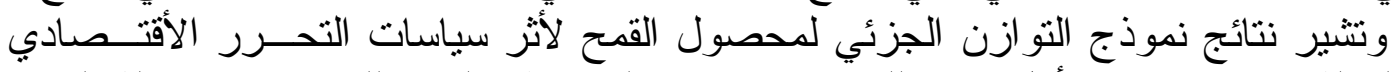

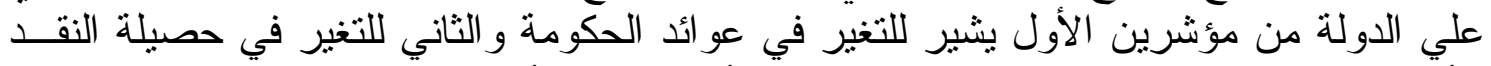

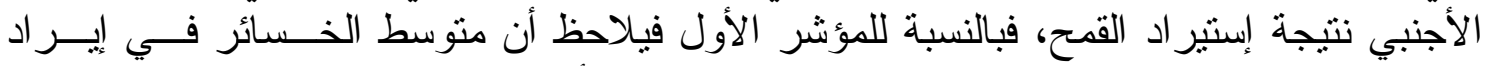

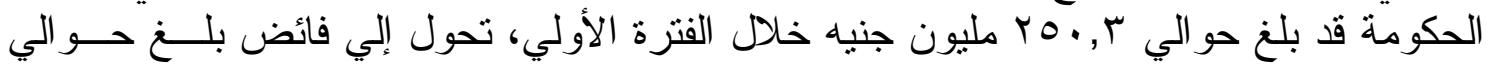

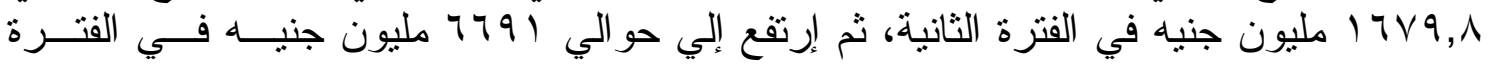

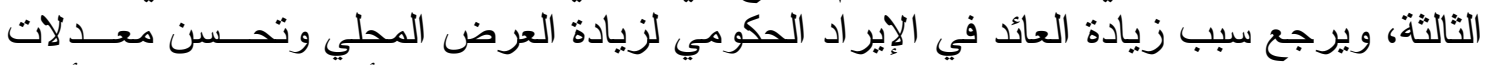

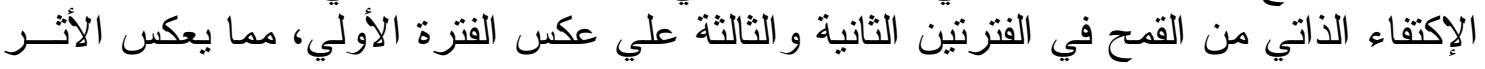

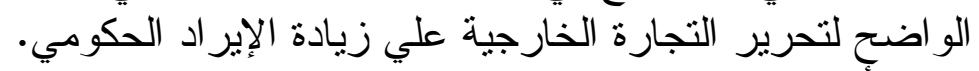

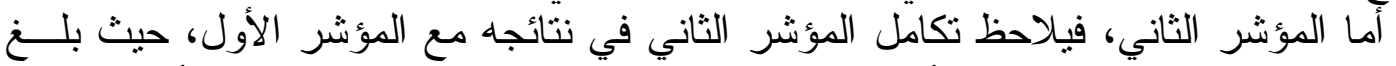

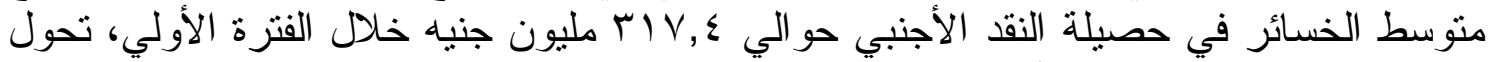

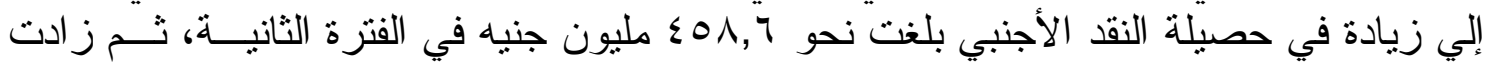

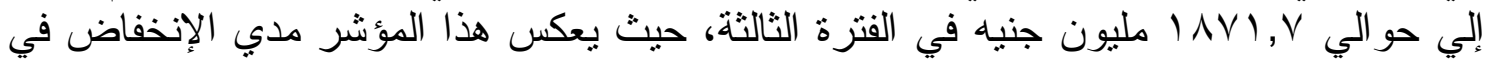




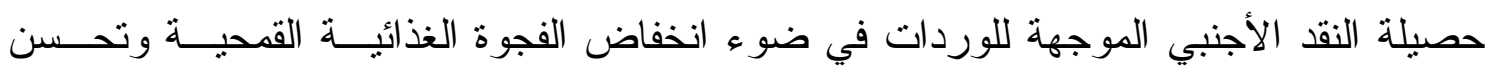
معدلات الإكتفاء الذاتي من القمح في الفترتين الثانية و الثالثة.

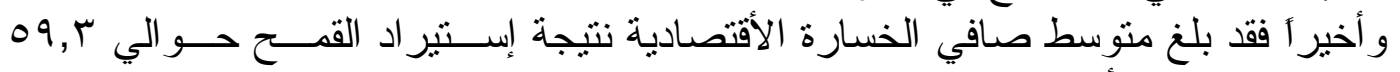

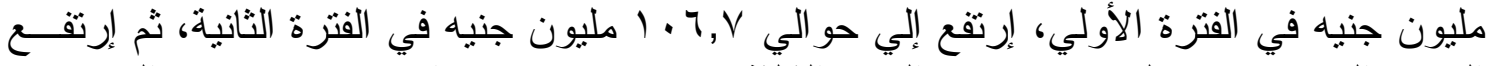

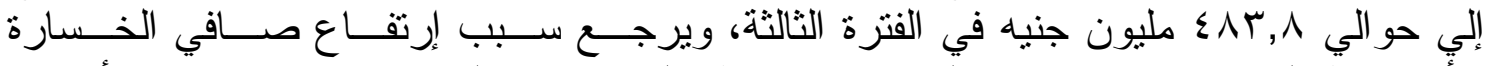

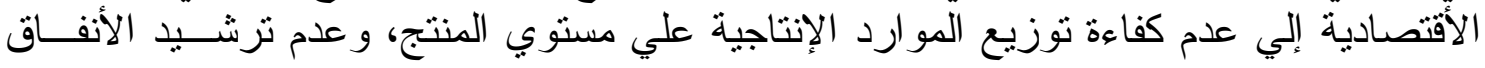
الإستهلاكي علي مستوي المستهلك. الملخص:

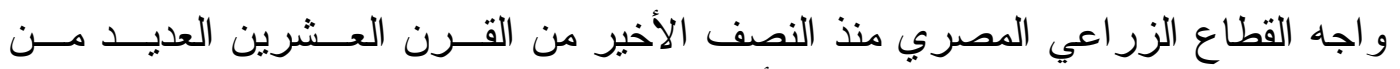

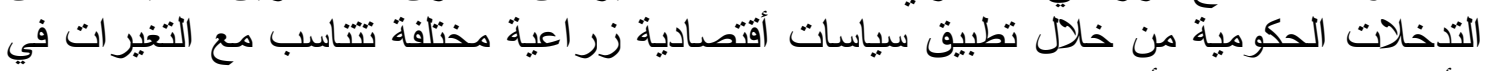

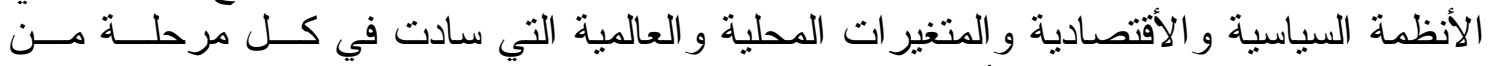

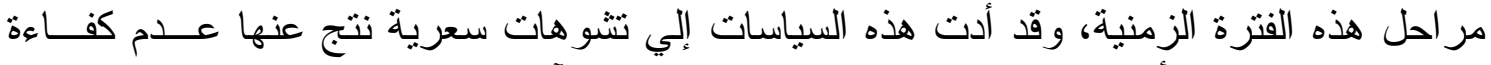

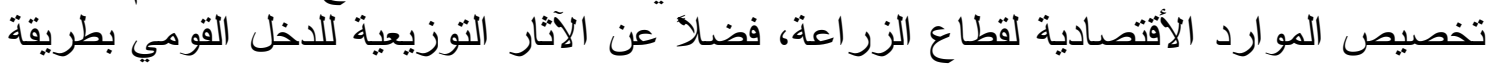

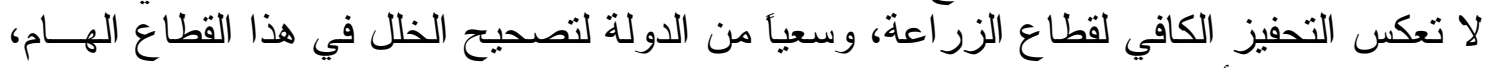

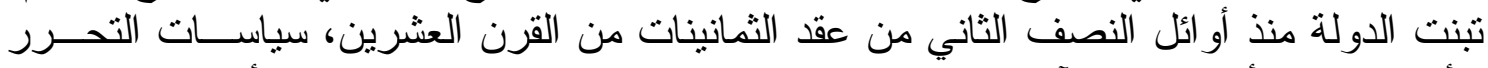

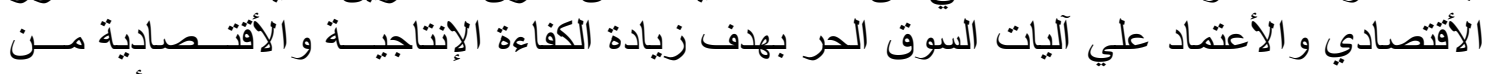

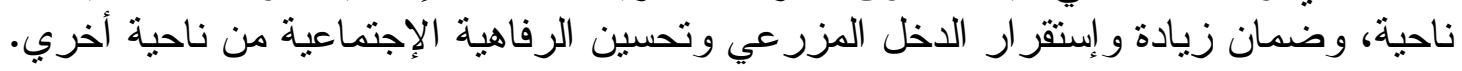

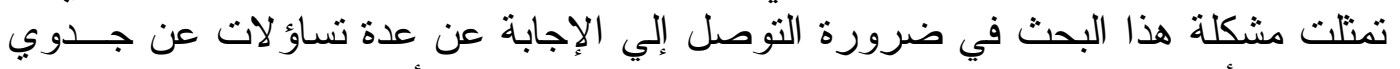

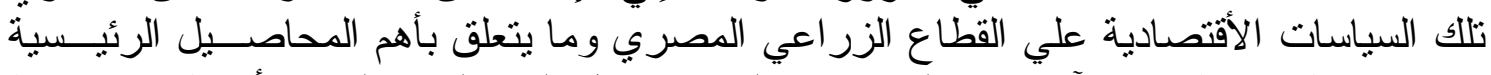

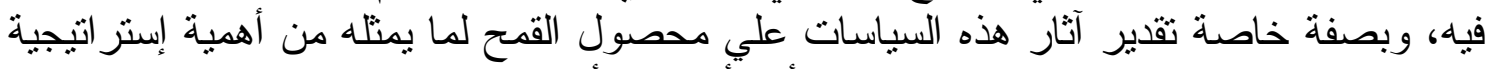

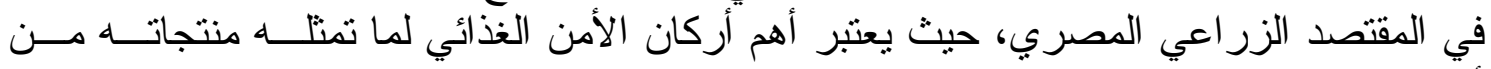

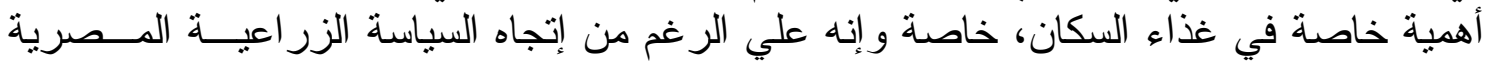

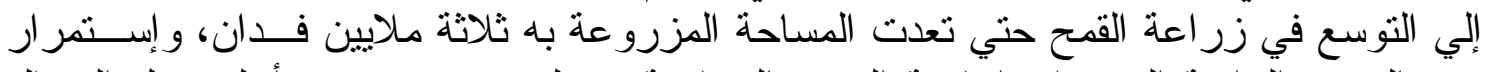

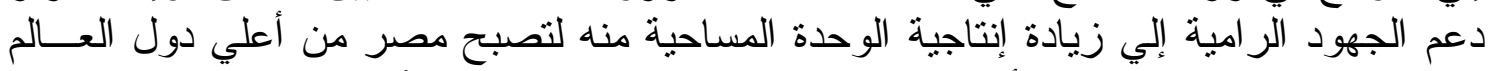

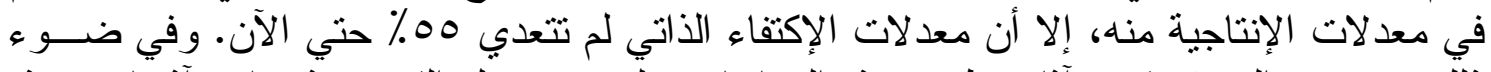

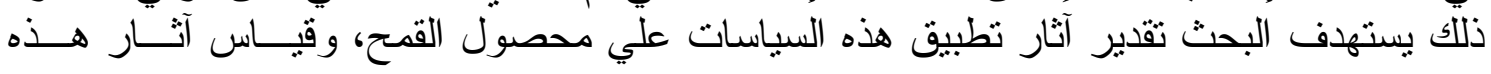

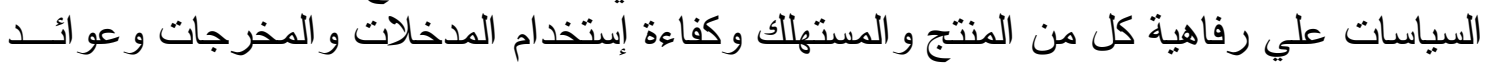

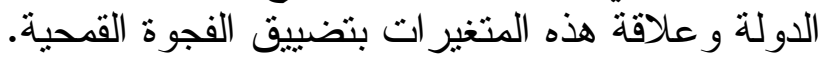
ووفقا لهدف البحث وطبيعة البيانات المتاحة، تم إستخدام أسلوب التحليل الوصفي الوصفي و الكمـي

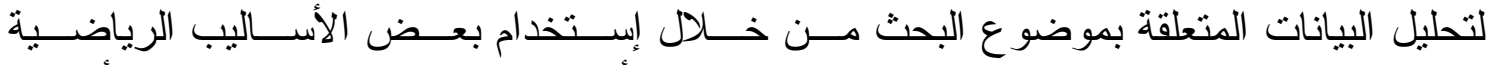

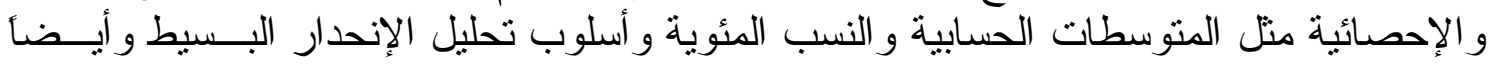

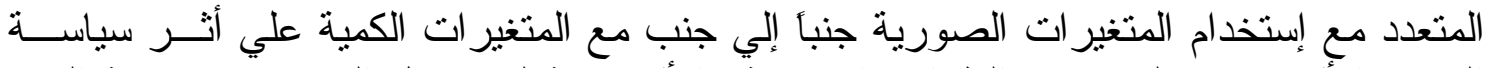

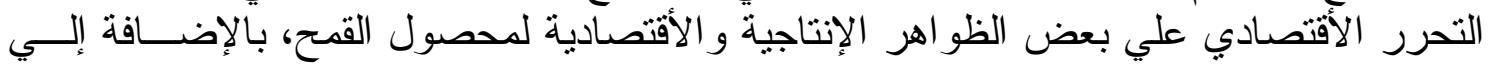

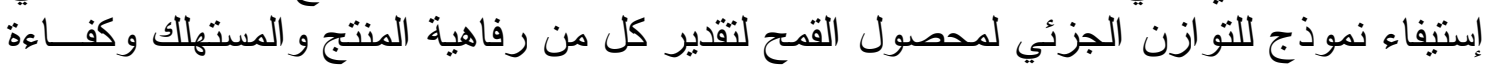

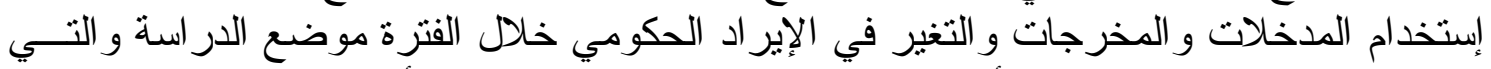

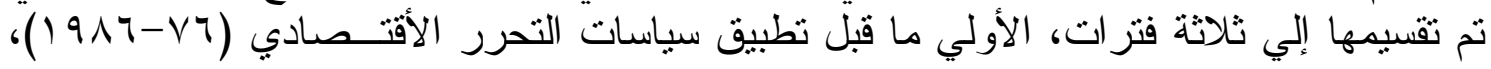

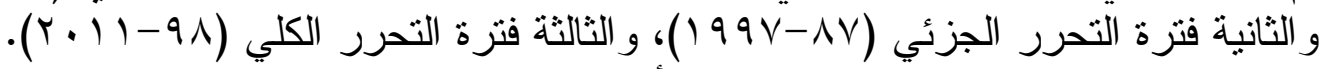

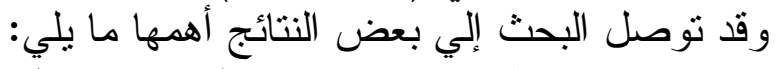

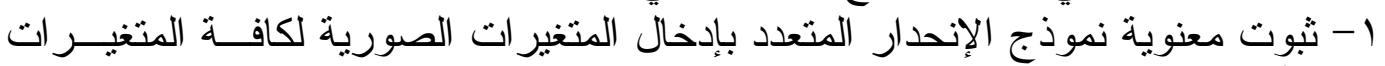

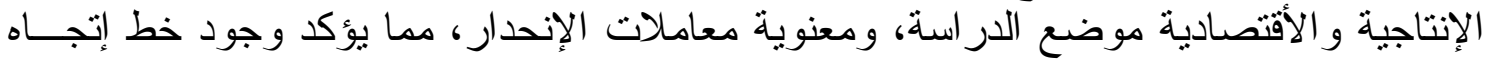

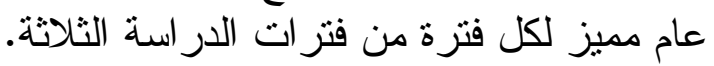

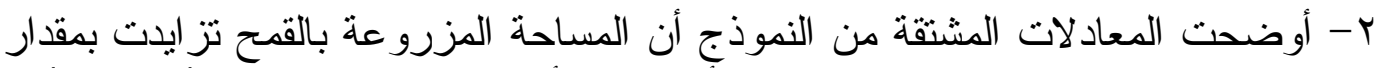

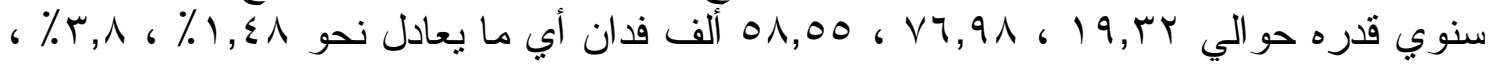




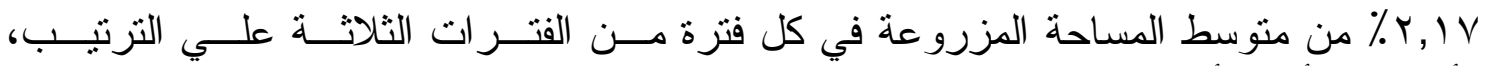

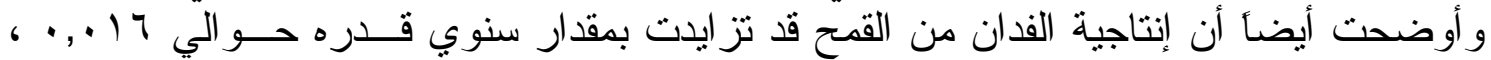

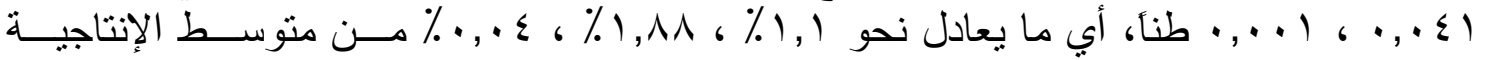

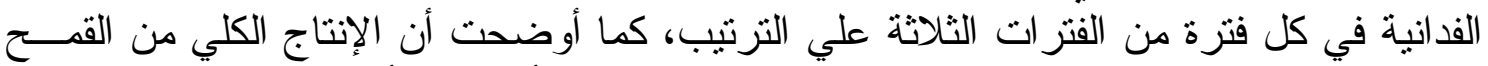

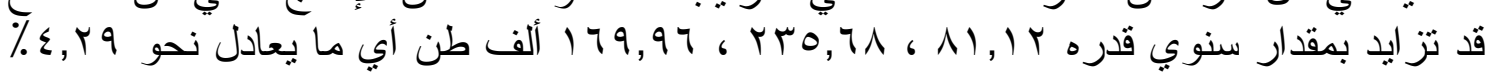

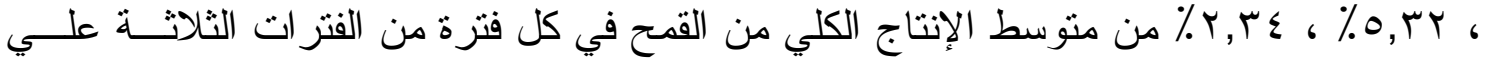

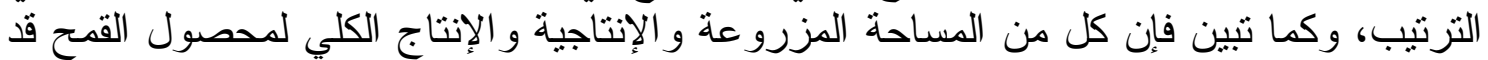

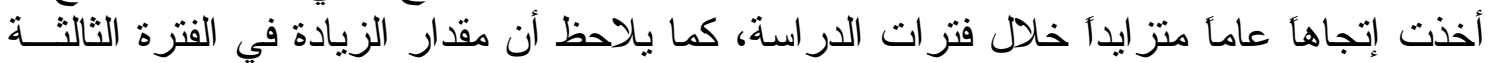

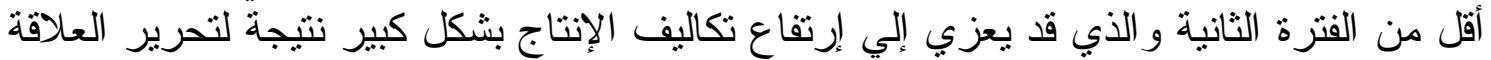

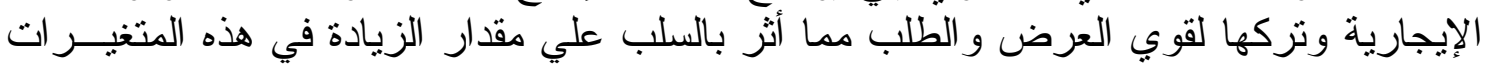
في الفتزة الثالثة.

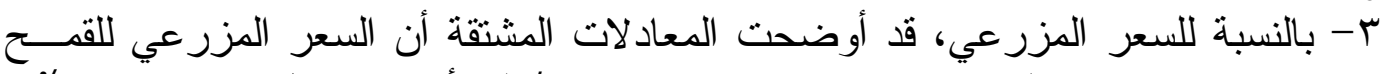

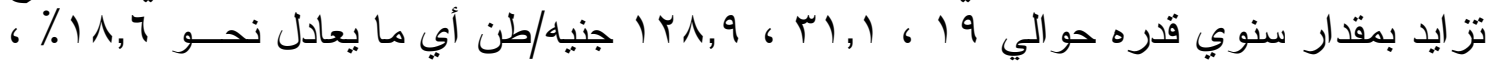

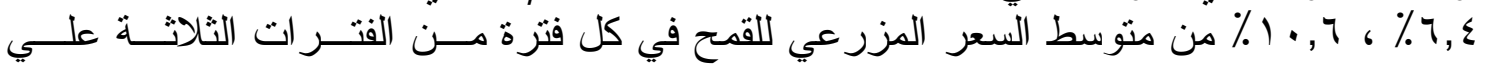

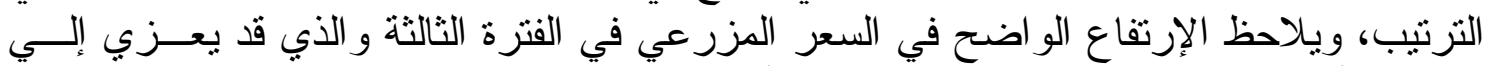

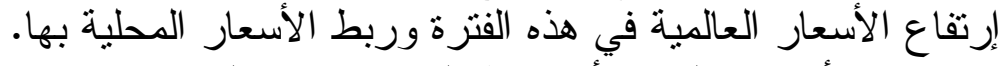

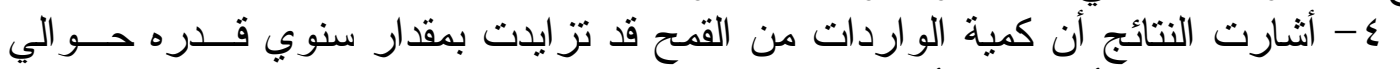

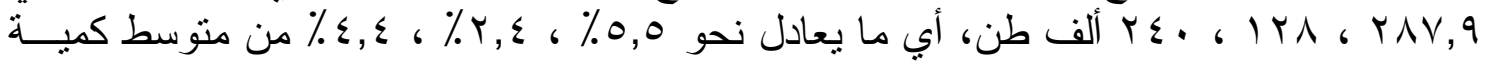

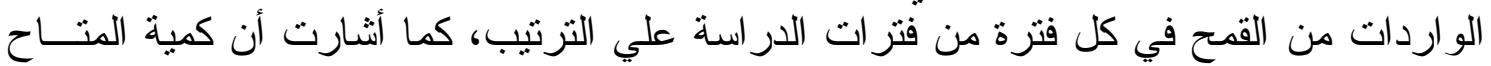

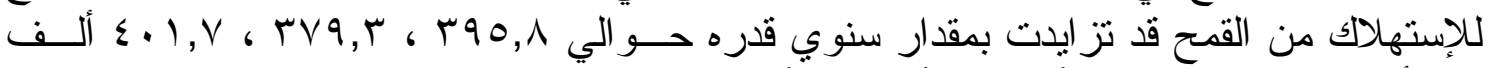

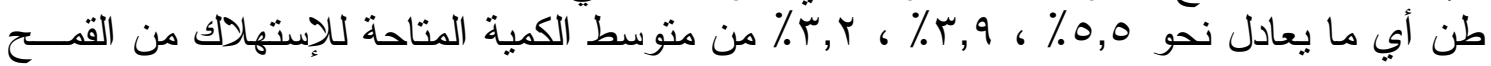

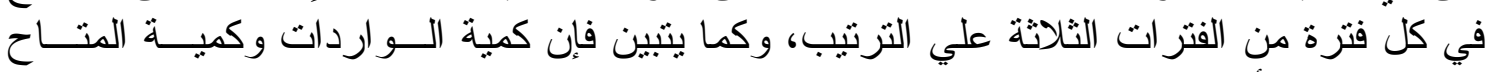

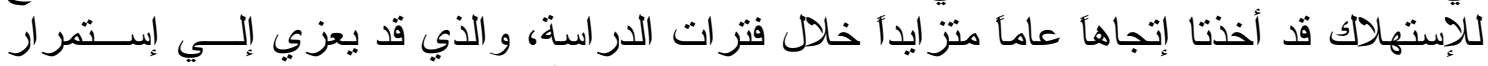

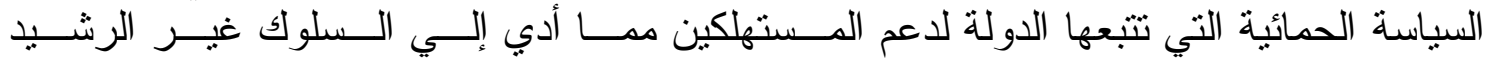

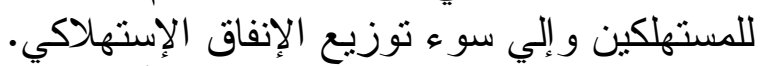

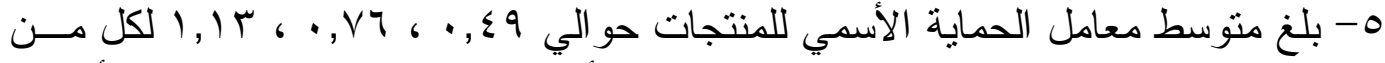

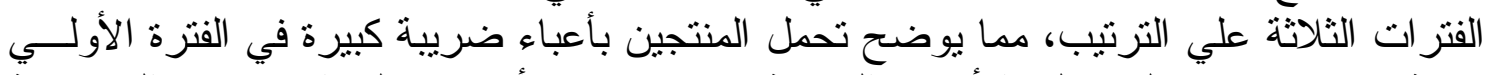

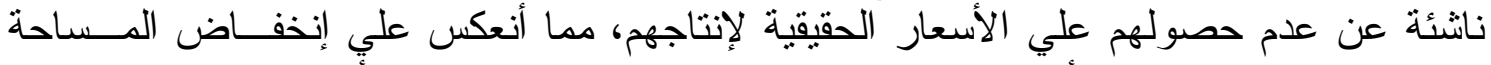

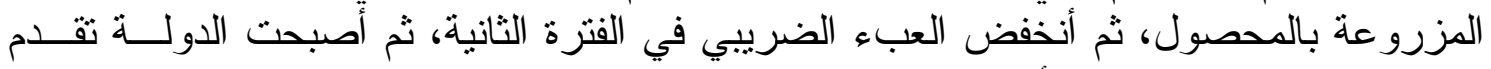

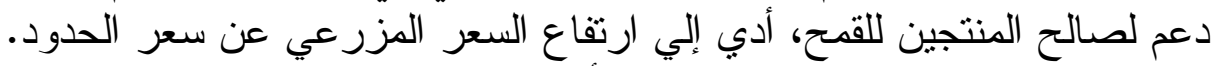

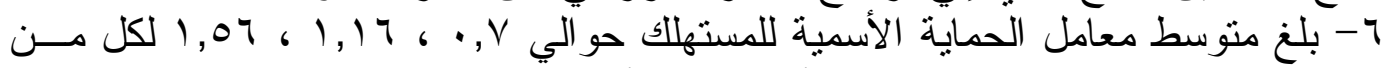

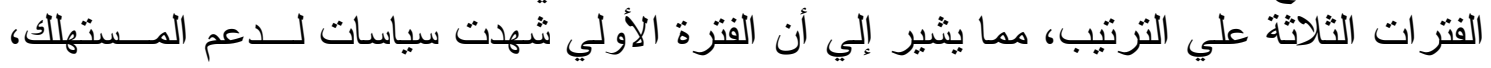

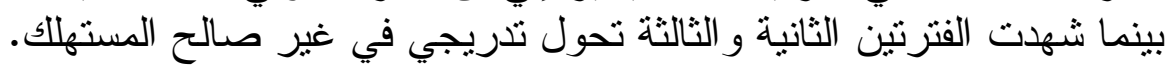

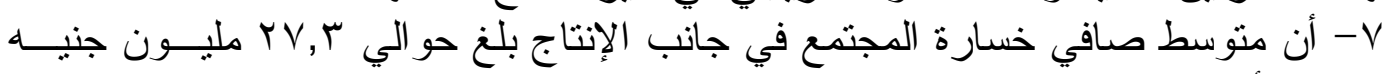

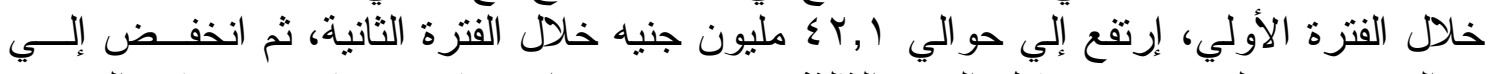

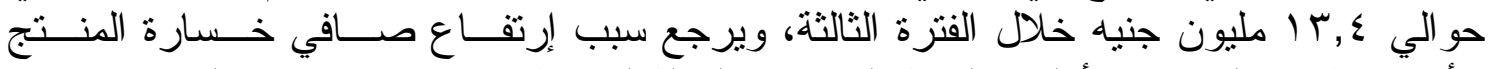

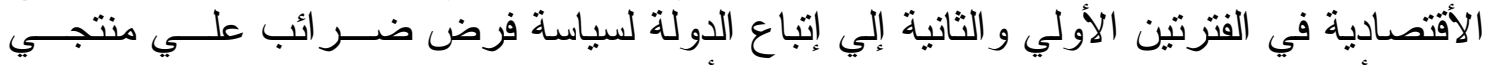

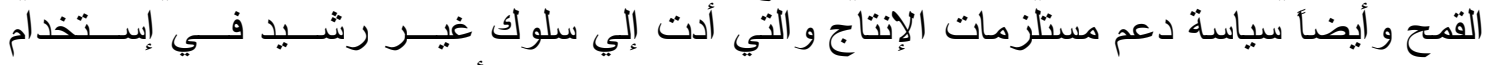

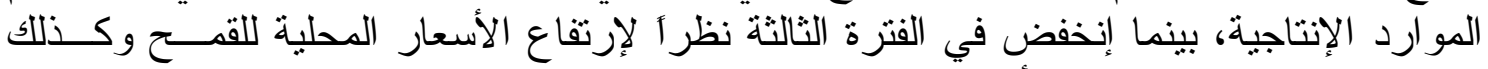

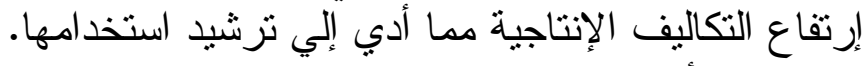

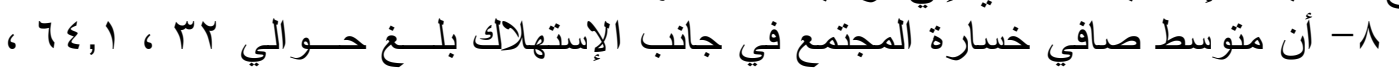

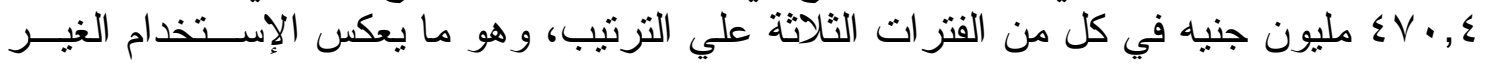


رشيد للسلعة، نتيجة لإتباع الدولة سياسة حمائية لدعم المستهلك، أدت إلي حالة من سوء توزيــع

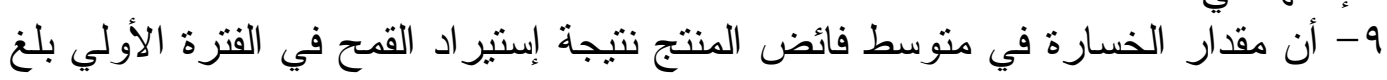
الإنفاق الإستهلاكي.

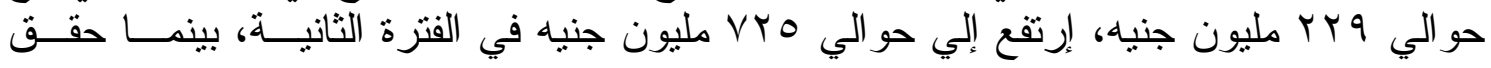

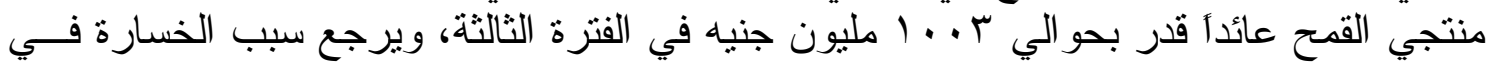

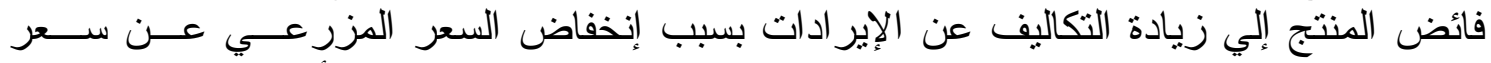

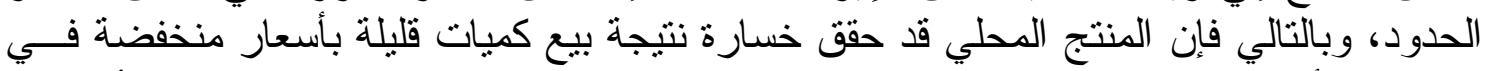

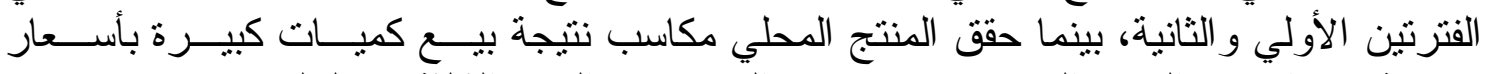

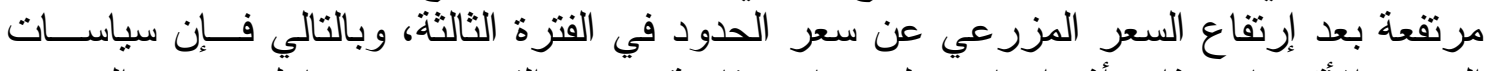

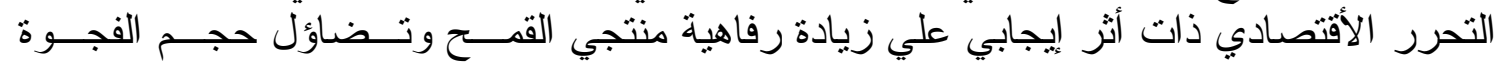
الغذائية نسبياً.

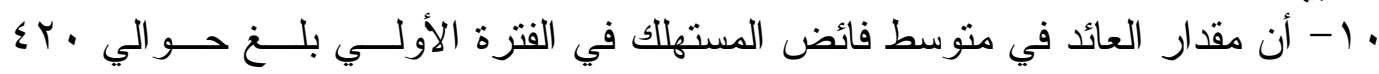

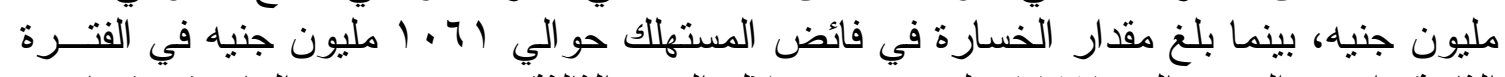

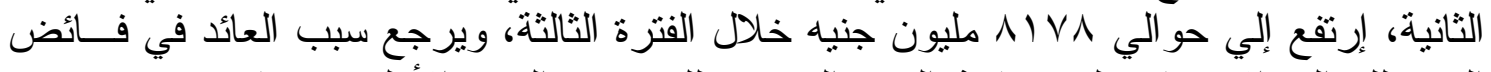

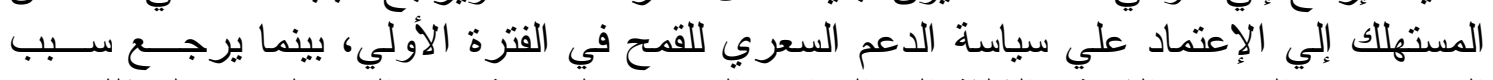

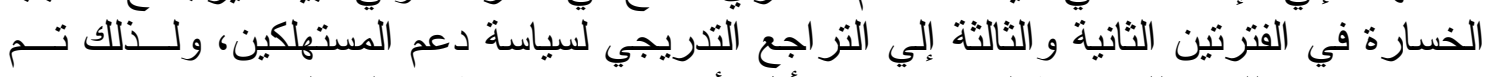

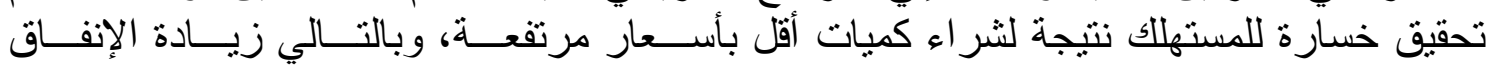

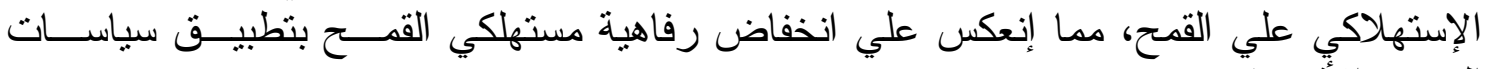

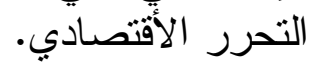

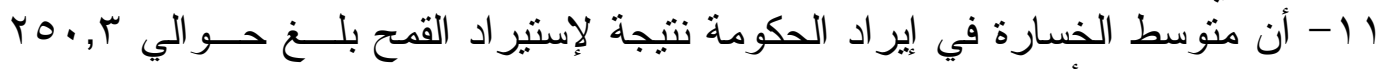

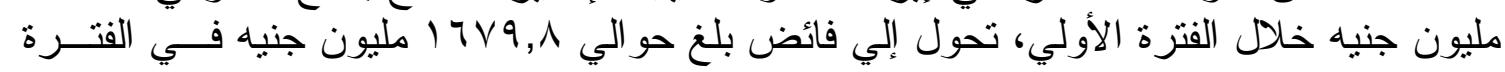

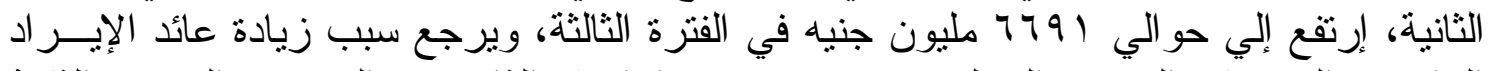

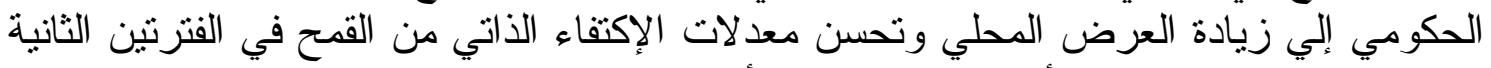

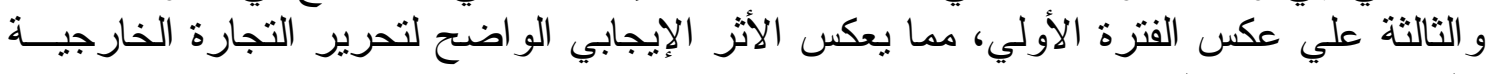

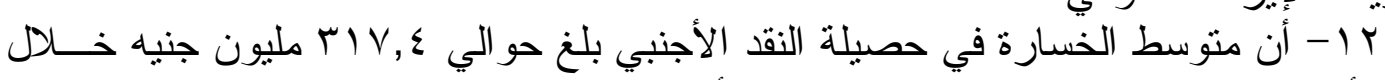

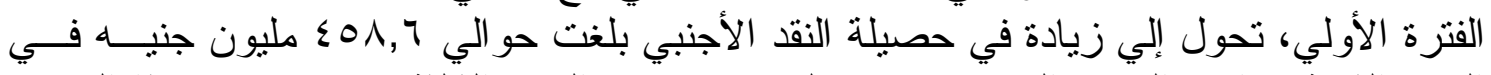

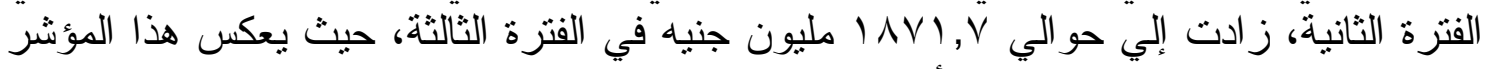

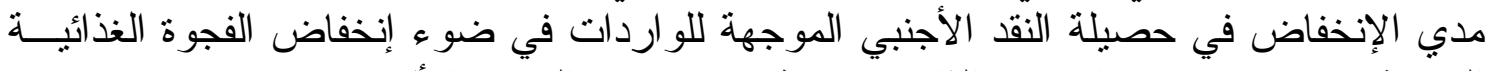

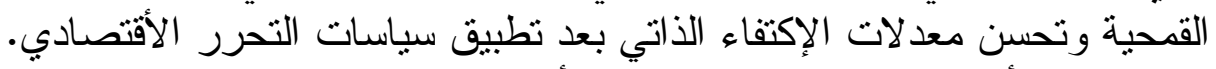

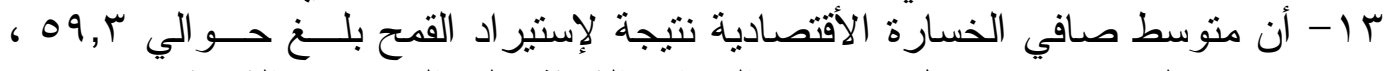

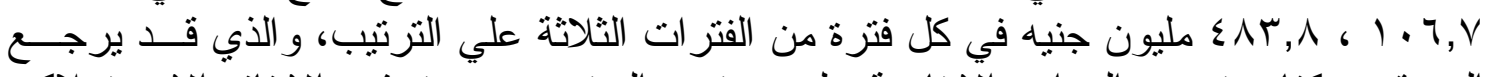

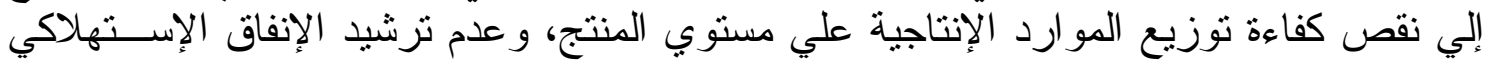
علي مستوي المستهرئك.

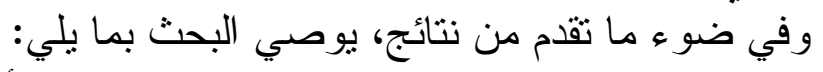

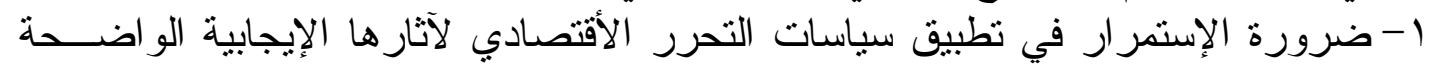

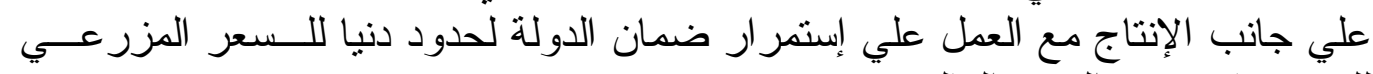

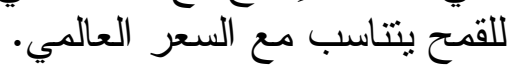

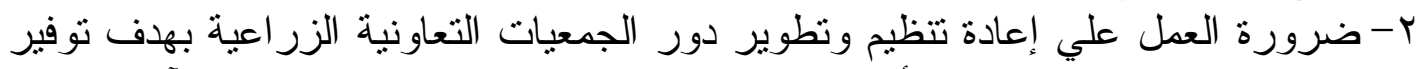

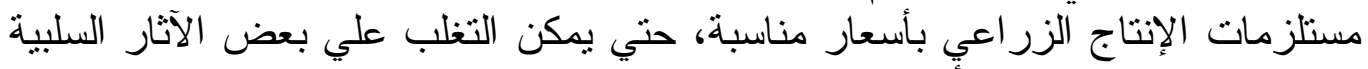

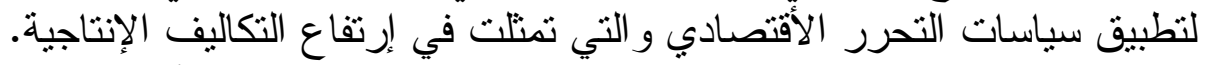

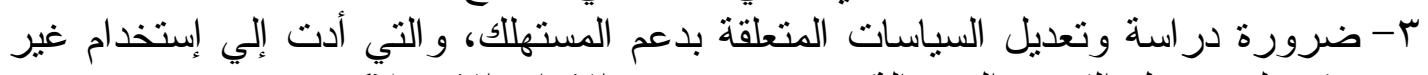

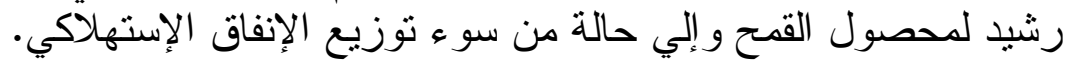


1- البنك الأهلي المصري، النشرة الأقتصادية، أعداد مختلفة.

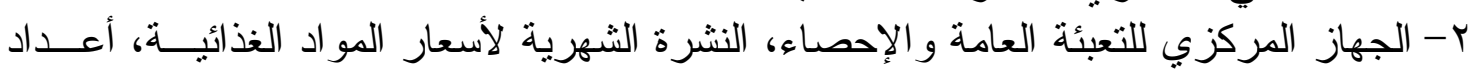
مختلفة. ب- الجهاز المركزي للتعبئة العامة و الإحصاء، نشرة إحــصاءات التجـــارة الخارجيــة، أعـــداد مختلفة.

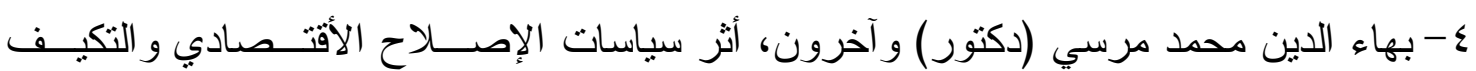

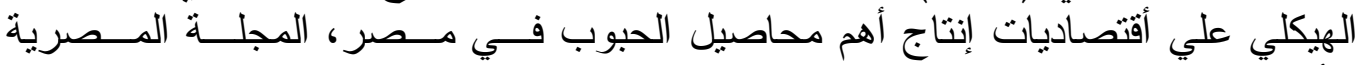

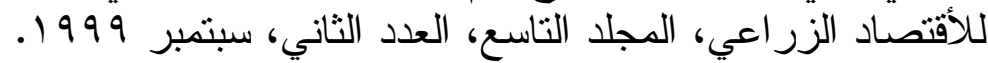

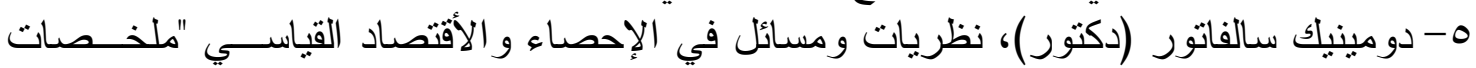

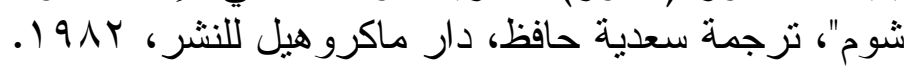

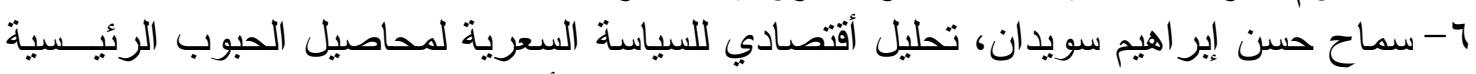

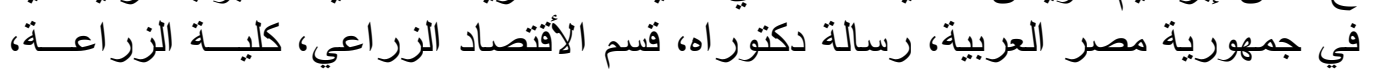
جامعة القاهرة، . 199 1.

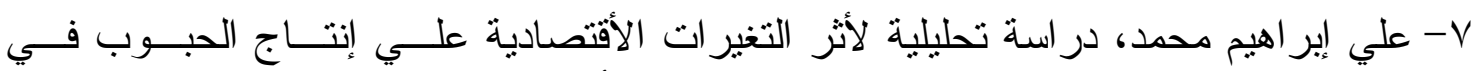

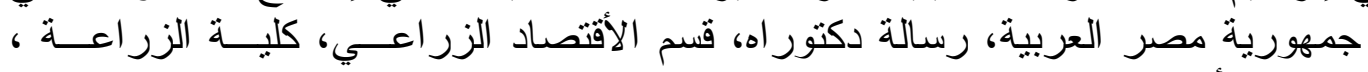

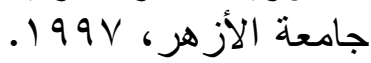

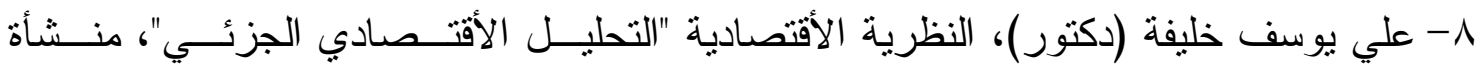

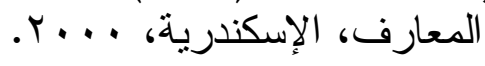

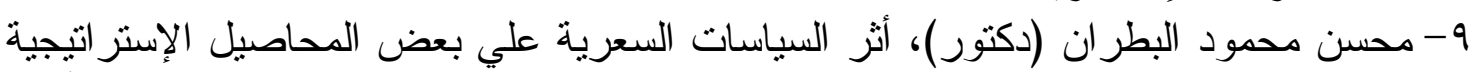

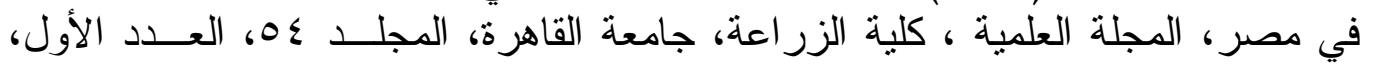

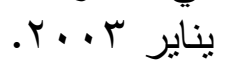

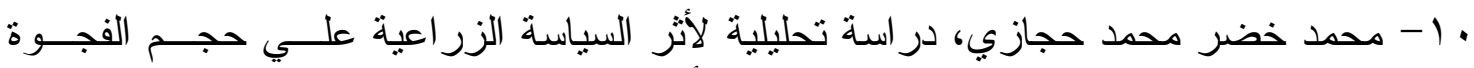

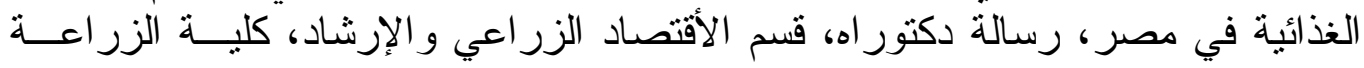

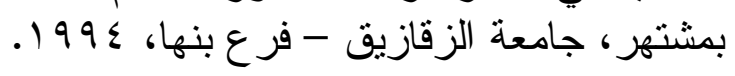

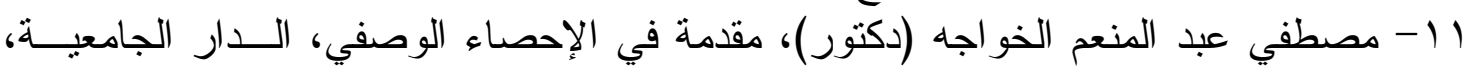

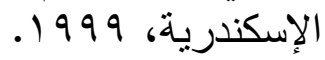

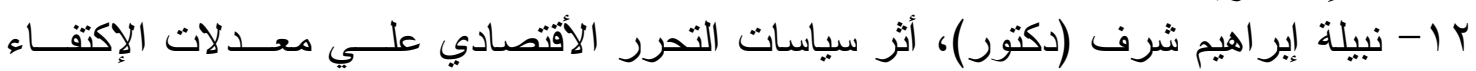

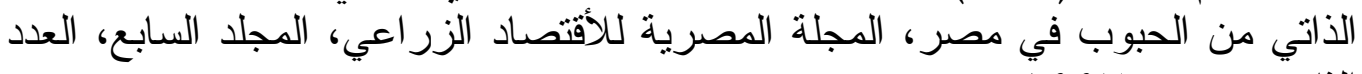

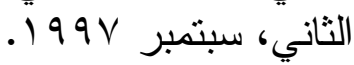

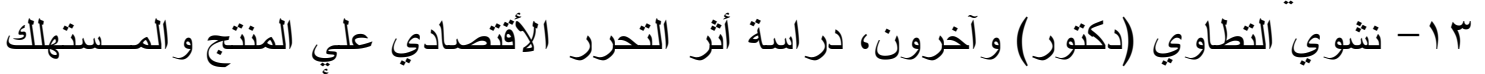

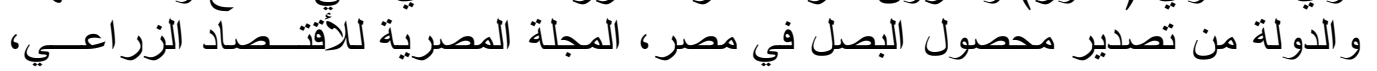

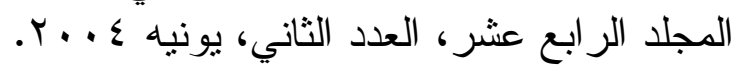

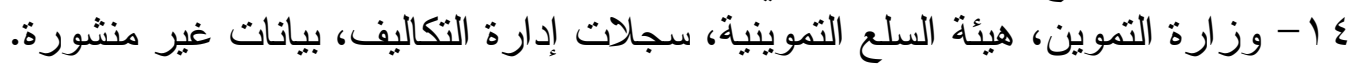

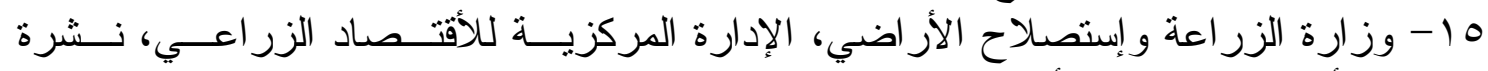
الأقتصاد الزرة اعي، أعداد مختلفة.

16- Isabelle Tsakok, Agricultural Price Policy, A Practitioner's Guide to PartialEquilibrium Analysis, Cornell University Press, London, 1990. 


\title{
Using Partial Equilibrium Model in Measuring the Impact of Economic Liberalization Policies on Wheat Crop in Egypt Hesham Aly El-Gendy
}

Agriculture Economic Research Institute

\begin{abstract}
:
The object of this study handle impact of economic liberalization policies on the producer, consumer and government for wheat crop in Egypt during the period 1976-2011 the time series period subject analysis is divided to three periods, the first one represent period before liberalization the second is partial liberalization, and the third is full liberalization.

To achieve the objective the study applied many different analysis tools for exploring these impacts so it has been used econometric methods, dummy variables regression for structural changes and partial equilibrium model for agricultural price policies.

Some of the results of the study are:

1- The economic liberalization policies have statistical significance effect with increasing area, yield, total production, farm gate price, quantity of consumption and quantity of import of wheat crop.
\end{abstract}

2 - The nominal protection coefficient for products is $0.49,0.76,1.13$ for the period before liberalization, the second is partial liberalization and the third is full liberalization, respectively.

3- The nominal protection coefficient for consumer is $0.70,1.16,1.56$ for the period before liberalization, the second is partial liberalization and the third is full liberalization, respectively.

4- Net economic loss in production is about 27.3 million EGP for the period before liberalization, it rised to about 42.1 million EGP for the second is partial liberalization due to support and decrease to about 13.4 million EGP in the third is full liberalization.

5- Net economic loss consumption is about 32, 64.1, 470.4 million EGP for the period before liberalization, the second is partial liberalization and the third is full liberalization respectively.

6- Change in producer surplus rised loss about 229, 725 million EGP in the period before liberalization and partial liberalization respectively, while it has reached a gain of about 1003 million EGP in full liberalization.

7- Change in consumer surplus has reached a gain of about 420 million EGP in the period before liberalization, while it has reached a loss about 1061, 8178 million EGP in partial and full liberalization periods respectively.

8- Change in government revenue rised loss about 250.3 million EGP in the period before liberalization, while it has reached a gain of about 1679.8, 6691 million EGP in partial and full liberalization periods respectively.

9- Change in foreign exchange rised loss about 317.4 million EGP in the period before liberalization, while it has reached a gain of about 458.6, 1871.7 million EGP in partial and full liberalization periods respectively.

10- The net effect loss about 59.3, 106.7, 483.8 million EGP during the three periods respectively.

Finally, the study recommends that the policy of liberalization have had obvious effects on wheat crop in Egypt. It is necessary to ensure minimum prices for wheat crop to such the domestic price with the world price. It is necessary to reactivate the role of agricultural cooperatives to reduce some of the negative effects of the policies of liberalization. Study and reform the policies of consumer subsidies to reduce the irrational behavior in the consumption expenditure. 